\title{
THE SPACING REQUIREMENT OF COCONUTS ON ATOLLS: RESULTS FROM FOUR SYSTEMATIC SPACING TRIALS IN KIRIBATI
}

\author{
By \\ J. J. F. BARR and K. TREWREN
}

\begin{abstract}
Four systematic spacing trials were planted between 1969 and 1973 on three islands in the Republic of Kiribati which have contrasting regimes of rainfall, in order to investigate the spacing requirements of coconuts in relation to rainfall (under atoll conditions). Two of the trials are on Kiritimati, which has an annual average rainfall of only $870 \mathrm{~mm}$; one is on Tarawa which receives $2043 \mathrm{~mm}$, and the fourth is on Butaritari which receives $3185 \mathrm{~mm}$. Three of the trials are in the form of an almost complete wheel, whilst the fourth consists off our fan-shaped sectors. The range of planting densities in all trials was from 126 to, 632palms per hectare, in 12 treatments.
\end{abstract}

Due to discontinuity of staff only one of the trials on Kiritimati was recorded during the period in which the coconuts came into, bearing but this showed fairly clearly that there is a relationship between precocity and planting density, with the palms coming into production earlier at the wider spacing.

During the period of maximum cropping of the palms the optimum planting density under conditions of $870 \mathrm{~mm}$ annual rainfall is outside of the range of densities covered by the trials, and somewhat less than 126 palms per hectare.

At $2000 \mathrm{~mm}$ rainfall, and for fertilized coconuts there is nearly equal yield per unit area of land within the range 169 to 304 palms per hectare, due to an inverse relationship between productivity per palm and number of palm per hectare. Number of fronds per palm and the rate of frond (and therefore bunch) production were inversely proportional to planting density, whilst trunk heights were directly proportional to planting density. The spacing to be chosen under these conditions will therefore be dependent upon other factors, such as the labour involved in digging the planting holes, whether the palms are to be intercropped, used for toddy or drinking nuts, whether the fronds are of significant value, and whether or not labour for subsequent maintenance is in short supply. In most situations, however, the lowest planting density which gives maximum productivity per unit area of land would be desirable.

There were shifts in the optimum planting density in response to rainfall during the previous season, from which it might be inferred that on islands which receive significantly less than 2000 $\mathrm{mm}$ rainfall per annum, and especially if the coconuts are not fertilized, the optimum population density is somewhat less than 169 palms per hectare. A convenient round figure under these circumstances is a spacing of 9 meters triangular, which gives a planting density of 143 palms per hectare.

Results from the trial on Butaritari were inconclusive due to only one year's full recording being obtained coupled with an unfortunate choice of site, but from the shifts which were observed in the trial on Tarawa in response to annual variations in rainfall it can be inferred that under high rainfall conditions a relatively high population density is optimal (but probably within the range 169 to 304 palms per hectare). 


\section{INTRODUCTHON}

The Republic of Kiribati lies astride the equator in the Central Pacific and consists of 33 islands divided into three main groups: the Gilbert Group, the Phoenix Group and the Line Group. The islands arc spread over a huge area of ocean - over 3,200 kilometers; from East to West and 1,600 from North to South. With the exception of Banaba, an island of dubious geological history of basically coral reef origin, which rises to a height of 81 meters, the islands arc ail low-lying atolls, seldom rising more than four meters above sea level.

The dominant species in the vegetation is the coconut palm, which covers an estimated $80 \%$ of the land area of the country (Catala, 1957). Coconuts arc absent mainly from within villages and areas of exceptionally low fertility. In the latter areas the vegetation. is dominated by the bushes Scaevola sericea and Tournefortia argentia.

Most of the stands of coconuts consist of naturally regenerating open woodland which is manipulated by man to a greater or lesser extent by the removal of plants of no economic value and the planting of coconuts in open spaces. The extent of this manipulation tends to be inversely proportional to the distance from habitation.

The traditional belief is that productivity per unit area of land is greatest at a high density of palms. On fertile soil on islands which receive abundant rainfall, this may be around 450 palms per hectare. On drier islands, on the other hand, coconut stands arc often maintained at a density of about 150 palms per hectare. Four systematic spacing trials were therefore planted between. 1969 and 1974 on three islands of contrasting rainfall, in order to investigate the optimum population density in relation to rainfall. It is thought that the first of these trials may have been the world's first application of Nelder's systematic spacing designs to a tree crop (see Nelder, 1962). The trials were designed by Mr. Ken Martin, who at the time was Biometrician at East Malling Research Station, Kent, United Kingdom.

\section{METHODOLOGY}

The four trials were planted at the following sites.

Trial No. Island

ERI Abatao Islet, Tarawa

ER2 Butaritari

ER3 Kiritimati, (Christmas Island)

ER4 Kiritimati, (Christmas Island)
Men Annual Rainfall (mm)

2,043

3,185

870

870
Date planted

December 1969

January 1973

May 1970

May 1970

The trials on Kiritimati Island were planted. in the form of a complete wheel, except, that the distance between the first and last spokes is slightly wider than the normal between-spoke distance. The trial on Tarawa is also a nearly complete wheel, but there is a small sector of disturbed ground missed out. The trial on Butaritari consists of four fan-shaped sectors. Two trials were planted on Kiritimati in order to compare results from two contrasting soil types. Trial number E R 3 is on a deep, loose sand with a lens of fresh water 1.5 to 2.4 meters below the surface. Trial number E R 4 is on a fine "lagoon mud" sand which has extensive biscuit-type hardpan encrustation on the surface and a saline water table 50 to $60 \mathrm{~cm}$ below the surface. 
The basic layout of all four trials is the same. The angle between the spokes is 4012 , and the ratio of distance between arcs increases with the constant, 1.076. The trial has been adapted from a square design into a triangular spacing by removing alternate palms in alternate spokes.

Treatments are as follows.

$\begin{array}{ccccc}\text { Treatment OLO } & & \text { Radii (m) } & \text { Area/plant (sq m) } & \\ 2 & & & \text { Plants/ha } \\ 3 & 38.64 & 15.82 & 632 \\ 4 & 41.57 & 18.32 & 545 \\ 5 & 44.73 & 21.20 & 476 \\ 6 & 48.12 & 24.54 & 407 \\ 7 & 51.78 & 28.42 & 352 \\ 8 & 55.71 & 32.90 & 304 \\ 9 & 59.93 & 38.08 & 262 \\ 10 & 64.48 & 44.08 & 227 \\ 11 & 69.38 & 51.02 & 196 \\ 12 & 74.64 & 59.04 & 169 \\ 13 & 80.31 & 68.36 & 146 \\ & 86.40 & 79.12 & 126\end{array}$

On Tarawa and Butaritari planting holes of at least one meter cube were dug and refilled with topsoil and organic matter before planting each seedling. On Kiritimati planting holes were, dug clown to, the water lens then refilled to $30 \mathrm{~cm}$ above the lens with such little topsoil as existed at each site. The seedlings were then planted at this level. At the site of E R 3, the holes have gradually refilled with sand washed and blown in, with the result that the boles of the trunks are now completely buried.

Unfortunately the site of the trial. on Butaritri was used as an air-strip during the Second World War, and growth has been extremely poor mi the areas in which the surface has been compacted for the runway. The problem has been investigated by Mr. K Martin (Biometrician) and it was eventually decided that two-thirds of the trial should be abandoned. The remaining part was still large enough to enable the original objectives to be realized.

Trial E R 4 on Kiritimati suffered from poor establishment, and although it was replanted, large parts again failed. Mr. Martin also investigated this problem, and recommended that half of the trial should be abandoned.

In the early 1970's a Nitrogen Fertilizer Trial was super-imposed upon part of the trial on Tarawa in such a way that fertilizer effects were confounded with those of spacing. This part of the trial has been excluded from the results up to and including 1984. Since March 1985 the trial was given blanket dressings of fertilizer, and the whole trial has been recorded. Fertilizer applications to the trial on Tarawa have been as follows.

In March 1985 a trace element mixture at $26 \mathrm{~g} /$ tree was applied by trunk injection. The mixture consisted of

$\begin{array}{ll}70 \% & \text { ferrous sulphate, } \\ 25 \% & \text { manganese sulphate, } \\ 4 \% & \text { zinc sulphate, } \\ 1 \% & \text { copper sulphate. }\end{array}$


In April 1985 potassium nitrate at $700 \mathrm{~g} /$ tree was broadcast within $50 \mathrm{~cm}$ of the trunk.

In September 1985 each tree was given

$400 \mathrm{~g}$ trace element mixture, in a hole in the soil adjacent to the trunk,

$700 \mathrm{~g}$ potassium nitrate,

$1,000 \mathrm{~g}$ IBDU (Isobutylidenediurea, 32\% N),

$500 \mathrm{~g}$ triple superphosphate.

The application of macronutrients has continued at six-monthly intervals at rates similar to those of September 1985.

The Butaritari trial was given $400 \mathrm{~g} / \mathrm{palm}$ of the trace element mixture in September 1985 and $700 \mathrm{~g} / \mathrm{palm}$ potassium nitrate in March 1986. No further applications of fertilizer were made.

The two trials on Kiritimati were given $500 \mathrm{~g} / \mathrm{palm}$ of a mixture which consisted of $71 \%$ ferrous sulphate and 29\% manganese sulphate in a hole in the soil next to the bunk in 1985.

Initially, only the first and last arcs (nos. 1 and 14) were treated as discard rows, but as the palms grew it became apparent that results from the closest spacing were inaccurate because the palms were leaning towards the "hub" of the wheel, thereby obtaining more light than they would if they were planted in a uniform stand at that spacing. Ares 2 and 3 were therefore excluded from the analyses. In the trial on Tarawa the hub of the wheel was later planted but this was too late to prevent the leaning effect.

At first plots of seven trees within the same are, with a discard spoke between plots, were used. This was later reduced to five-tree plots with discard spokes and finally to single tree plots without discard spokes.

In most years the variates which have been recorded or derived, and analysed, have been as follows. The recordings were carried out once each year. The variates have been analysed both in terms of the individual year's results and the cumulative mean over the years.

1. number of fronds per palm,

2. number of fronds produced in one year,

3. number of nuts per palm in bunches 5 to 8 ,

4. total number of nuts per palm excluding bunches 1 to 4 ,

5. estimated number of nuts per hectare in bunches 5 to 8 ,

6. estimated total number of nuts per hectare excluding bunches 1 to 4 ,

7. estimated number of nuts per hectare per annum,

8. trunk height,

9. annual increment in bunk height.

These variates were chosen because the size of the trials made it impossible with the resources available to harvest the nuts on a regular basis, and if they were allowed to fall from the palms it was quite impossible at the closer spacing to be sure which -palm a particular nut had come from. 
Bunches 1 to 4 were not recorded because most of the nuts in these bunches would be shed well before they reached harvestable size. Variates 5 and 6 were derived from variates 3 and 4 by multiplying numbers of nuts per palm by palms per hectare. Variate 7 was derived from variate 5 by multiplying mean number of nuts per hectare per bunch by number of bunches per hectare per annum, discounted by $40 \%$ to allow for natural nut-fall before maturity in bunches 5 to 8 .

The 1984 results were analysed by Mr. K Martin by Analysis of Variance. Since 1985 results have been analysed by Mr. K Ryder by fitting linear and quadratic regression curves to the data. The site of the trial on Tarawa is rather uneven, so depth to the water lens has been used as a covariate in the analyses. Since fertilizer applications began number of palms/ha has also been used as a covariate for the trial on Tarawa. This is because fertilizer has always been applied on a per palm basis, thus the rate of fertilizer application per hectare is directly proportional to palm density, thus masking some of the effects of inter-palm competition for nutrients at close spacing.

\section{RESULTS AND DISCUSSION}

From the time of planting until 1976 vegetative growth was recorded in terms of frond production and palm height. Although a wealth of information is available, this is beyond the scope of this paper, the information on yield being of paramount importance. From 1976 until 1983 no results are available from three, of the trials due to discontinuity of staff, but information on the relationship between planting density and precocity is available from trial E R 3 on Kiritimati.

\section{The relationship between planting density and precocity}

First yield results from the trial on Kiritimati became available in 1977, seven years after planting, although a few scattered palms had flowered in earlier years (it must be remembered that Kiritimati has an average annual rainfall of only $870 \mathrm{~mm}$ ). In both 1977 and 1978 there was a highly significant $(\mathrm{P}<0.001$ in all variates) negative linear relationship between planting density and yield, in terms of number of spathes per palm, number of immature nuts per palm and number of immature nuts per hectare (Figures 1 to 3 ).

\section{Yield and frond production parameters, 1983 to 1992}

\section{a) The trial on Kiritimati}

Trial ER 3 on Kiritimati was recorded from 1983 to 1986, after which recording was discontinued due to financial constraints. Unfortunately, due to prolonged drought, virtually no crop was produced in 1985 and 1986. Trial ER 4 was first recorded in 1984, but yields were so low, and plot-to-plot variation was so great that they could not be analysed.

The results from 1983 and 1984 arc presented graphically in Figures 5 to 10 . In all except one of the variates there is a clear negatively linear relationship between planting density and the recorded values, although in some yield parameters there are significant deviations from the linear model (see Figure 6). The exception is trunk heights in trial ER 3, in which the relationship is linear and positive, as it is also in the trials on Tarawa and Butaritari. A positive relationship might be expected because at the higher plant densities the palms are struggling to reach the sunlight and therefore growing taller. In trial ER 4, however, the site of the trial is especially unfavourable, and competition for moisture and nutrients results in shorter palms at the higher planting densities (Figure 10). Although the yield results from ER 4 could not be analysed the means do present an interesting picture, and are presented graphically in Figure 8.

From the variate number of fronds per palm, it appears that in both trials on Kiritimati the critical number below which little or no crop can be expected, is 27. During the drought years of 
1985 and 1986 the mean values at the widest spacing in trial ER 3 were 22.0 and 24.8. In 1986 die range of values in trial ER 4 (12.2 to 29.6) is much greater than in ER 3 (16.4 to 24.8), and it is likely that in the former trial the pattern of yield results in 1987 would have been similar to that of 1984 (Figure 8) .

Fig. 1. Spacing Trial ER 3, Kirimati Number of Spathes per Palm, 1977 \& 1978

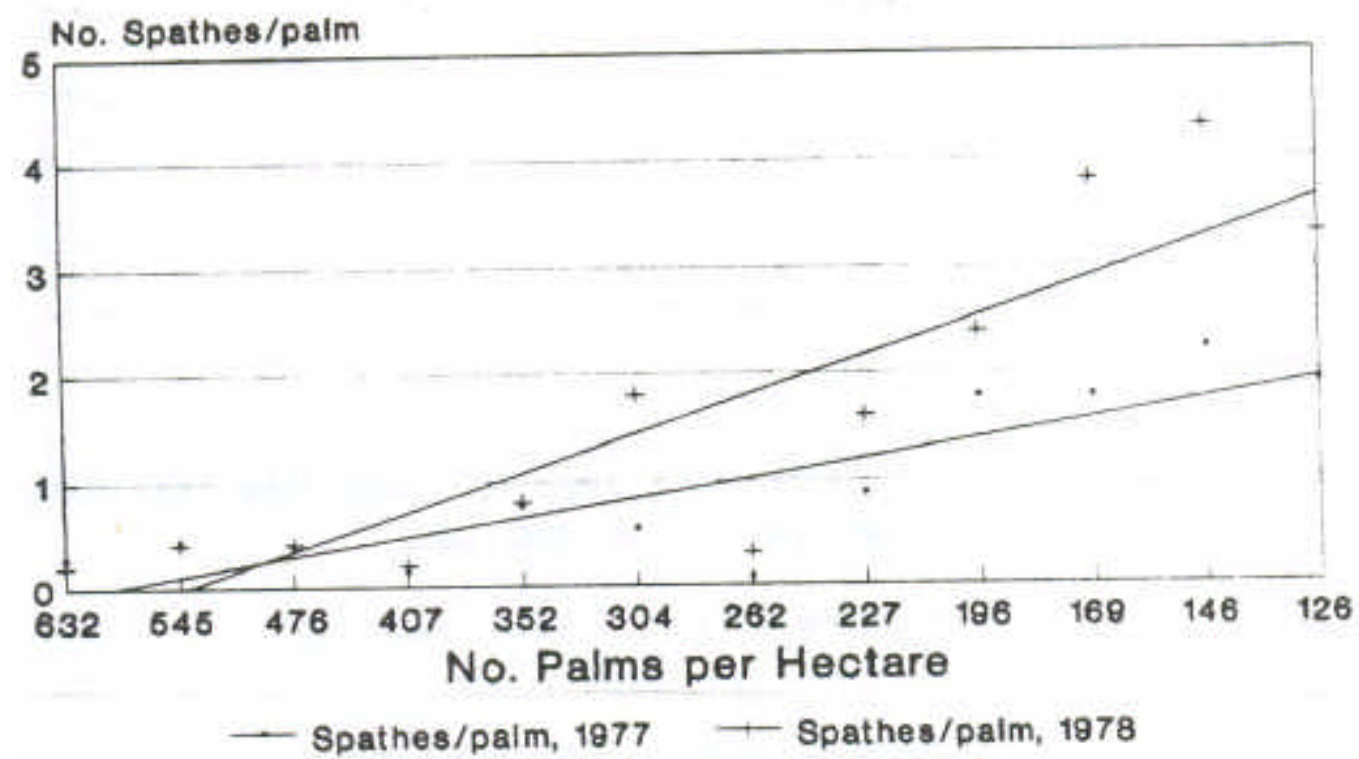

Fig. 2 Spacing Trial ER3, Kiritimati Number of Immature Nuts/palm, 1977 \& 1978 No. Immature Nuts/paim

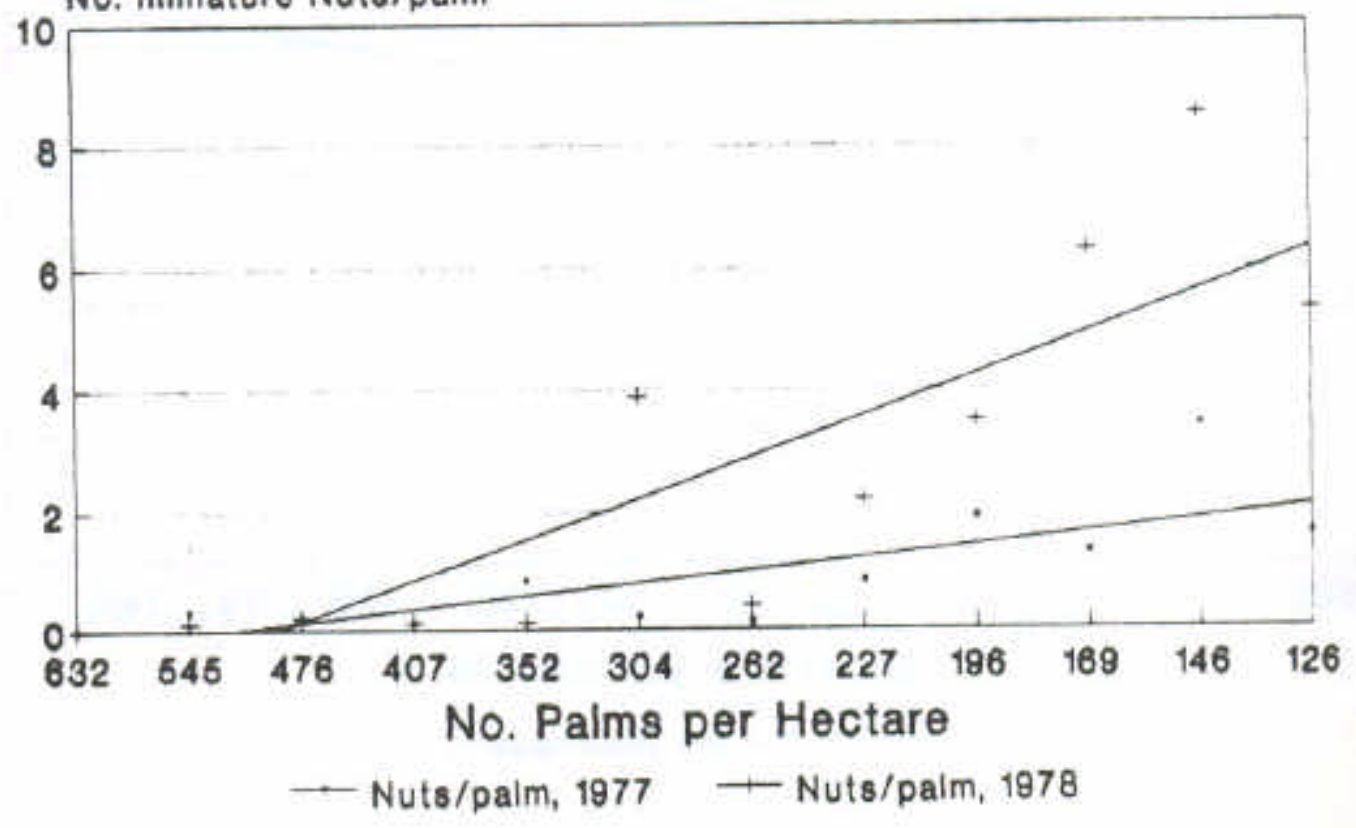


Fig 3. Spacing Trial ER 3, Kiritimati Number of Immature Nuts/ha, 1977 \& 1978

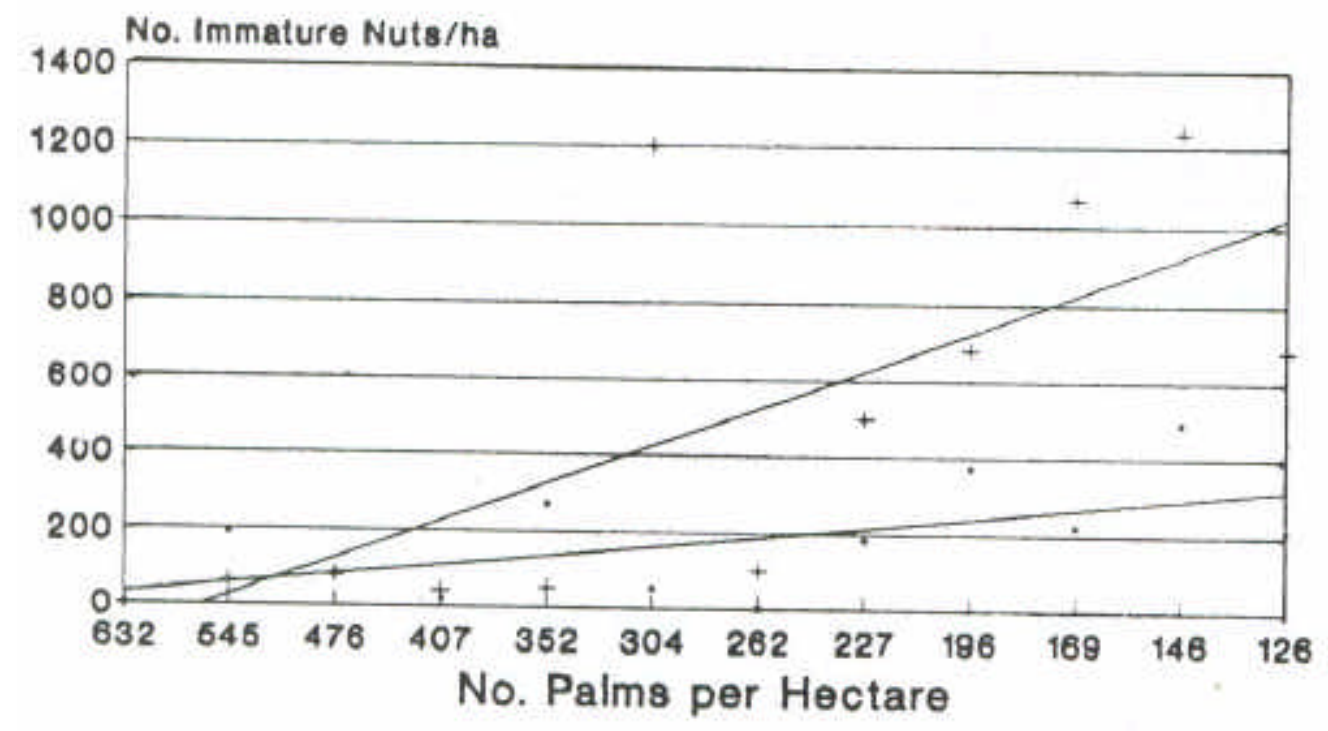

$\rightarrow$ Nuts/ha, $1877+$ Nuts/ha, 1978

Fig 4. Spacing Trial ER 3, Kiritimati Number of Fronds Produced, 1977 \& 1978

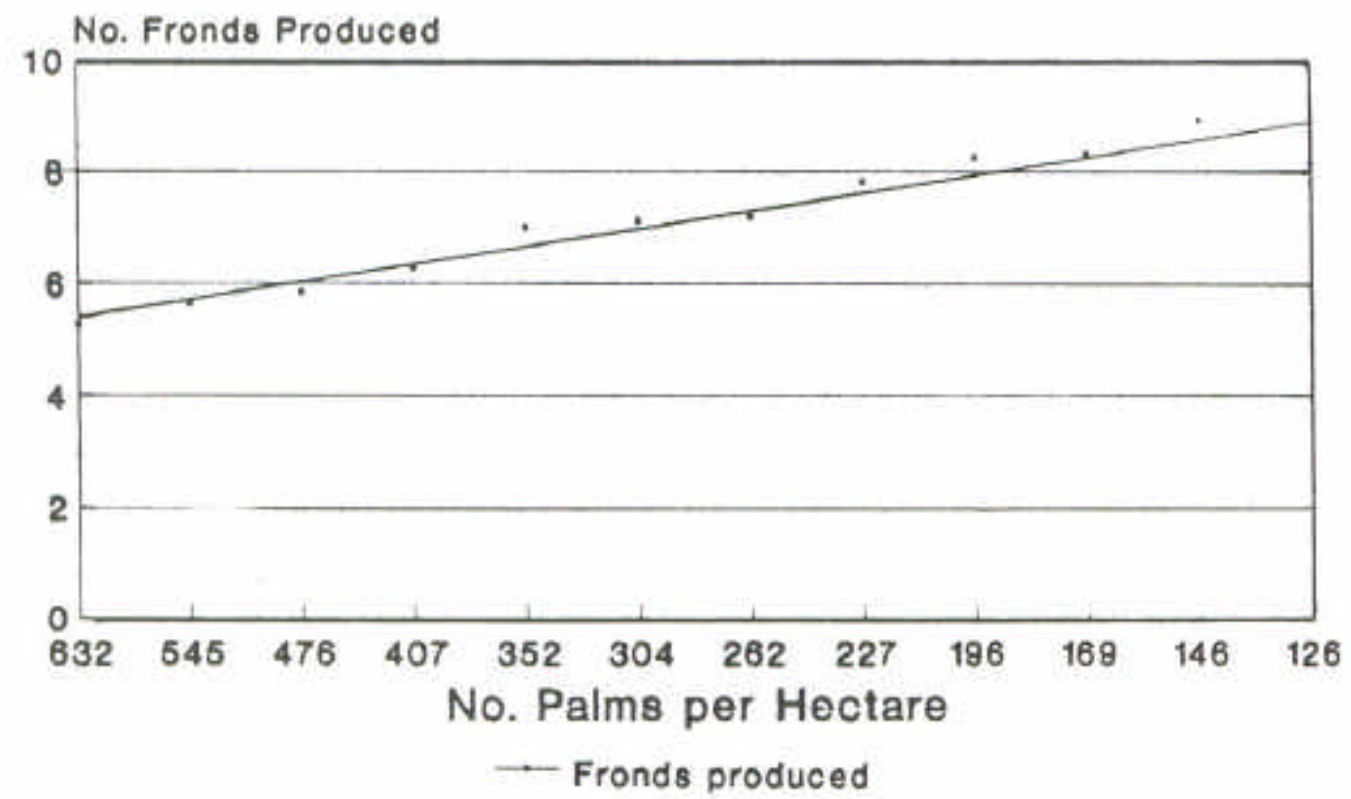


Fig 5. Spacing Trial ER 3, Kiritimati Nut Production Parameters, 1983

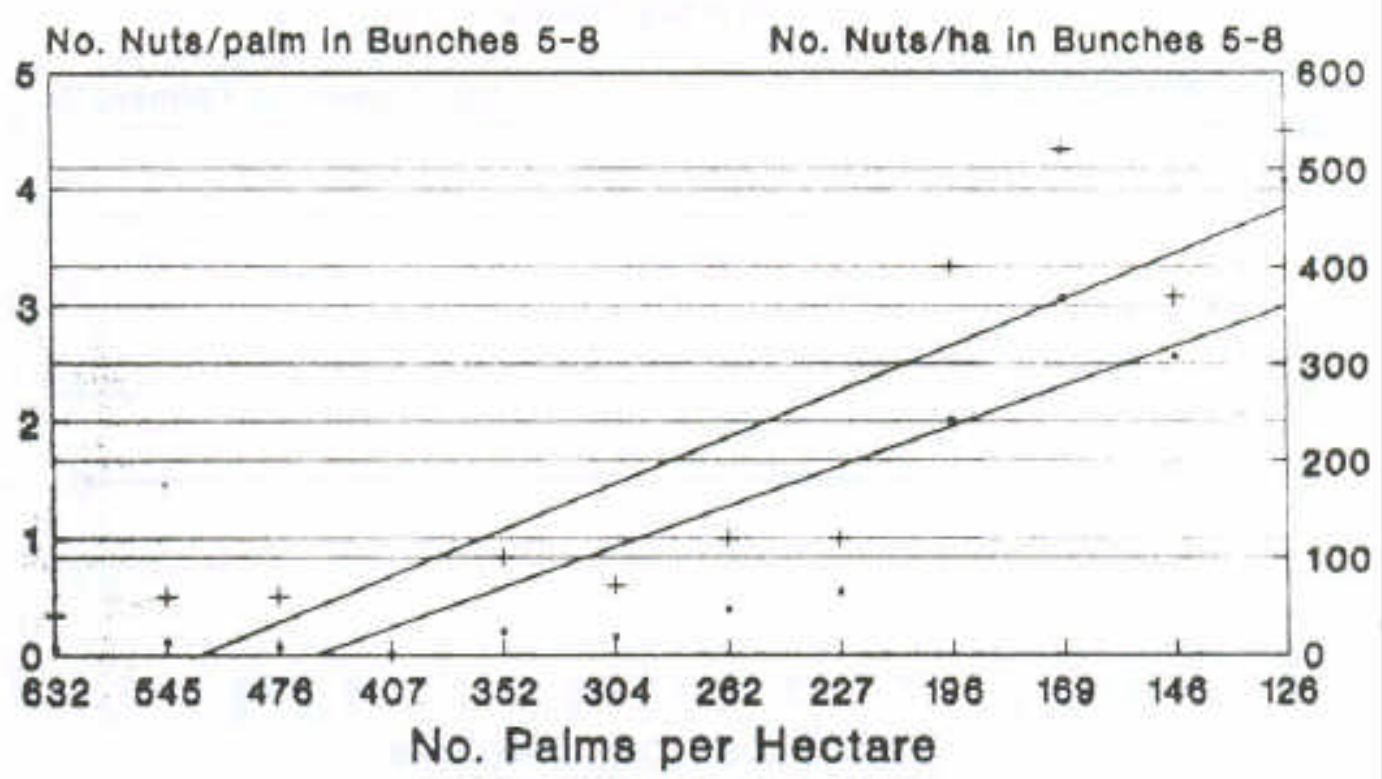

$\rightarrow$ Nuts in Bunches 5-8 No. Nuts/ha

Fig 6. Spacing Trial ER 3, Kiritimati Nut Production Parameters, 1984

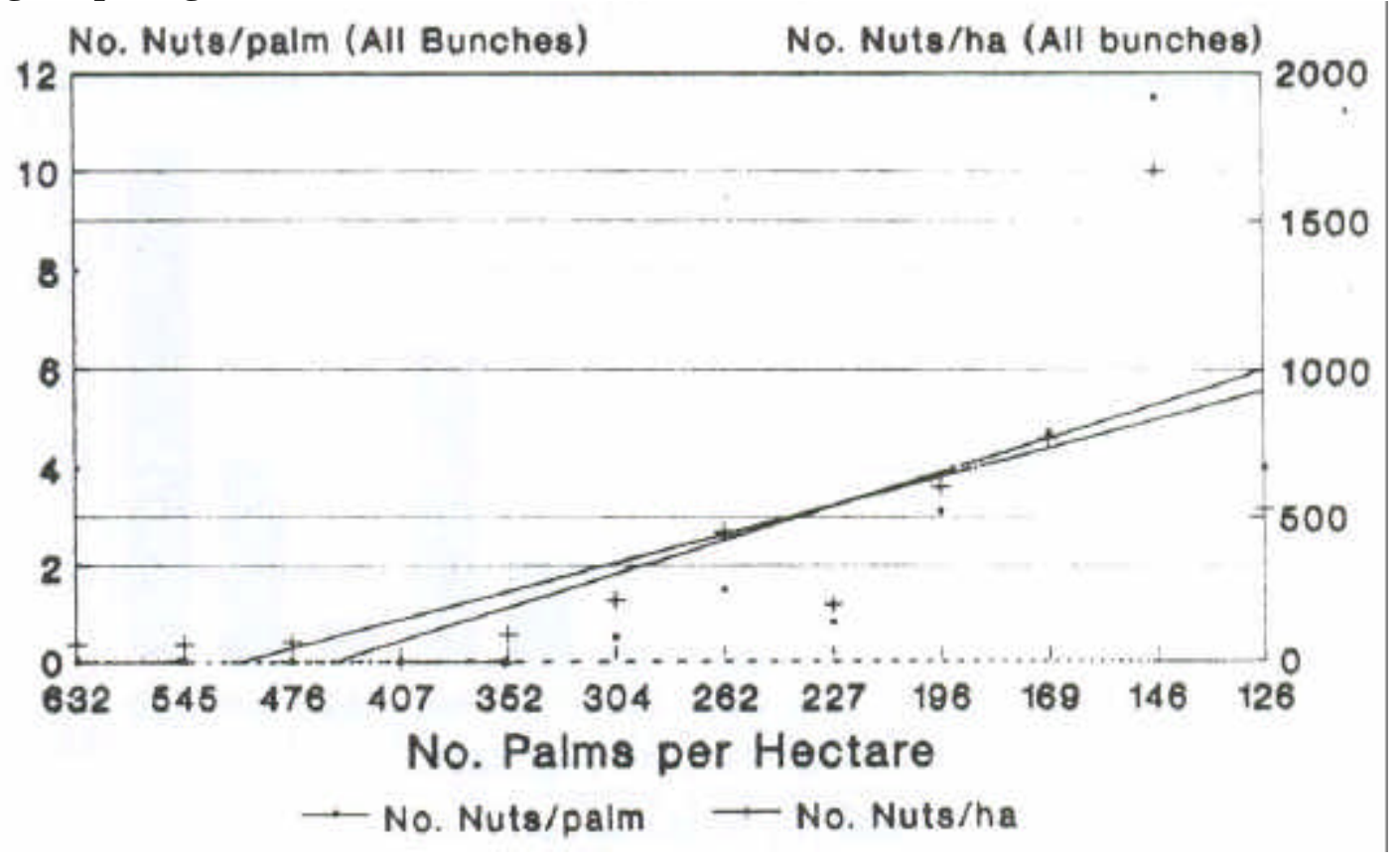


Fig 7. Spacing Trial ER 3, Kiritimati Number of Fronds per Palms/3-palms and Number of Flowering Palms/3-palm plot

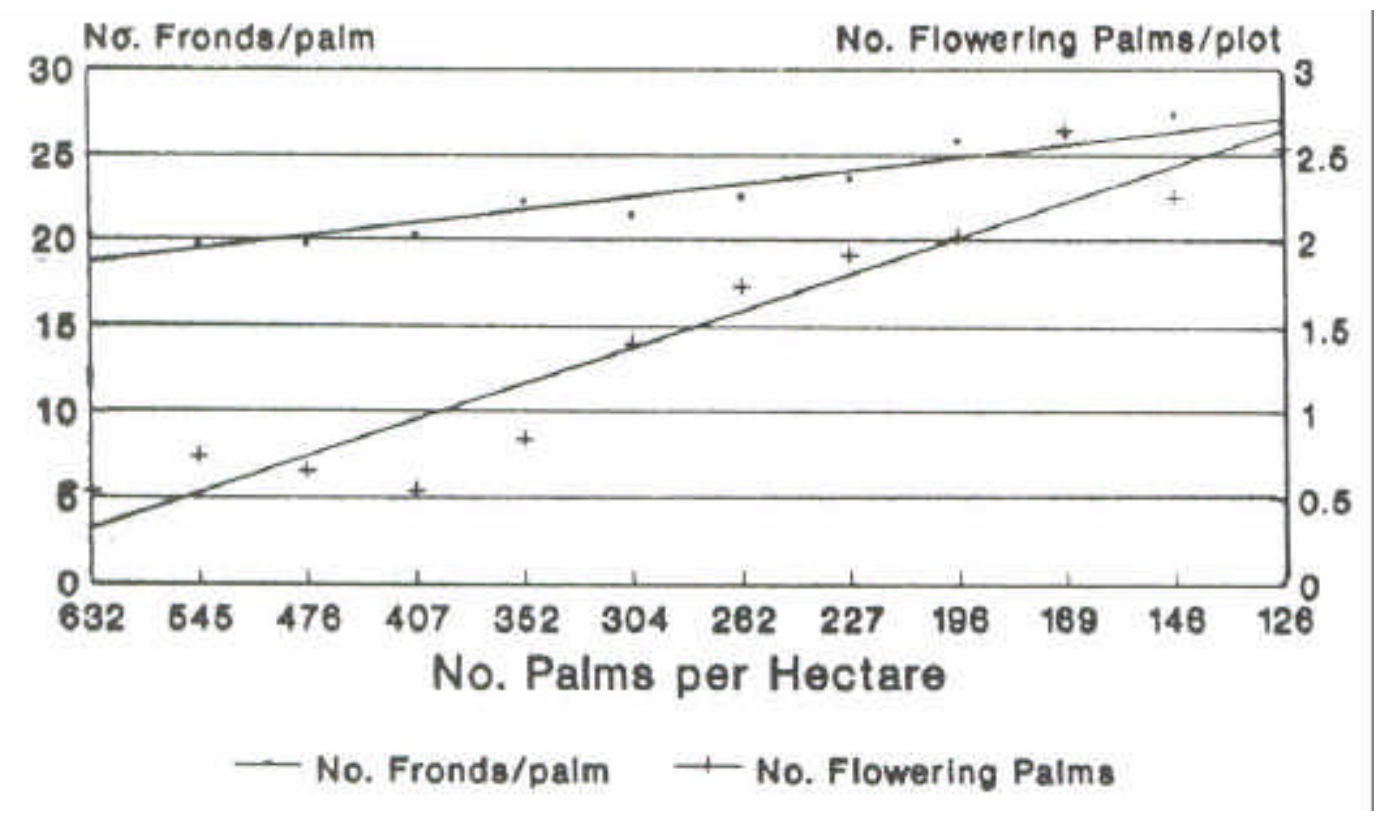

Fig 8. Spacing Trial ER 4, Kiritimati Number of Nuts per hectrare, 1984

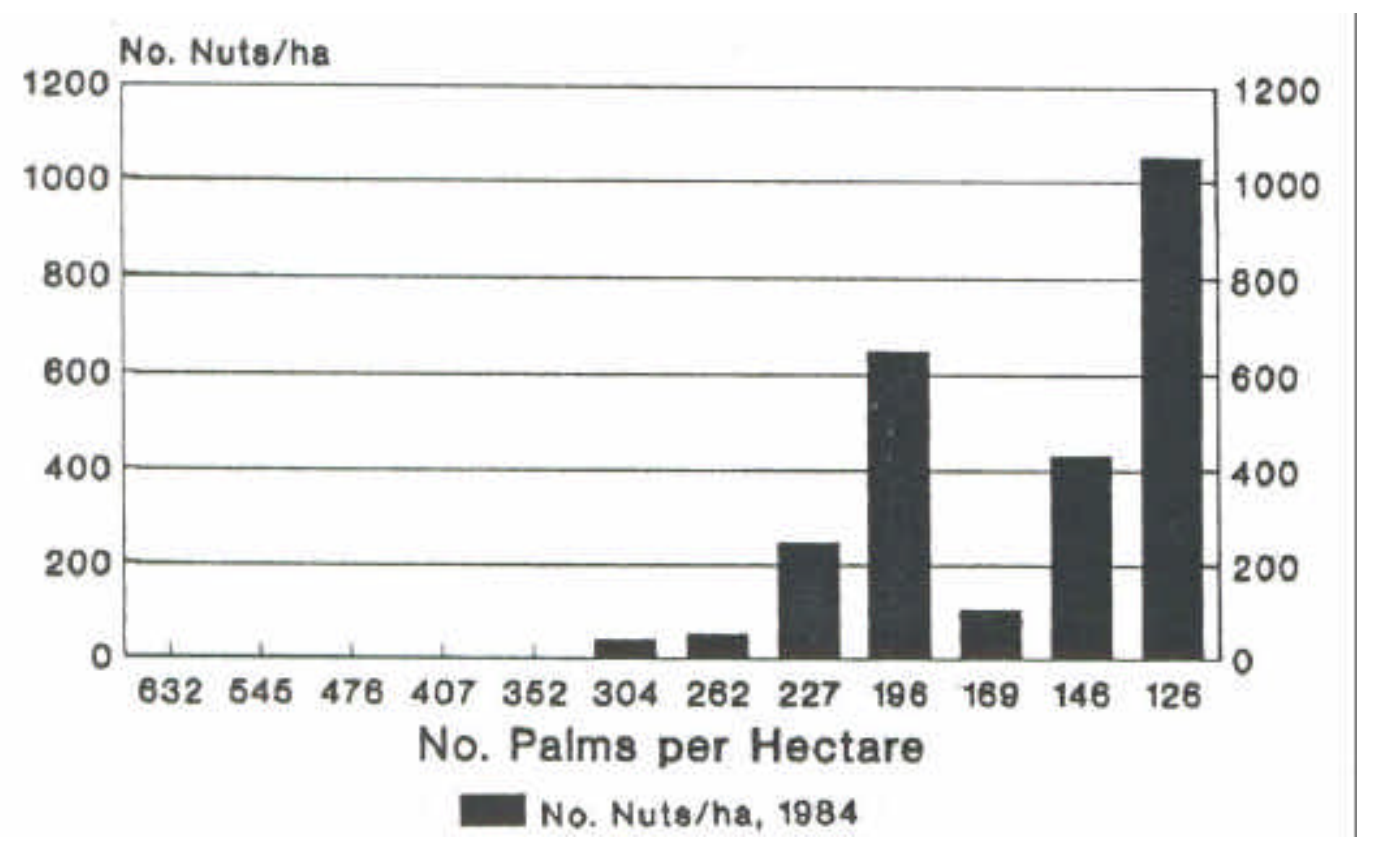


Fig 9. Spacing Trial ER 4, Kiritimati Number of Fronds per Palm, 1984

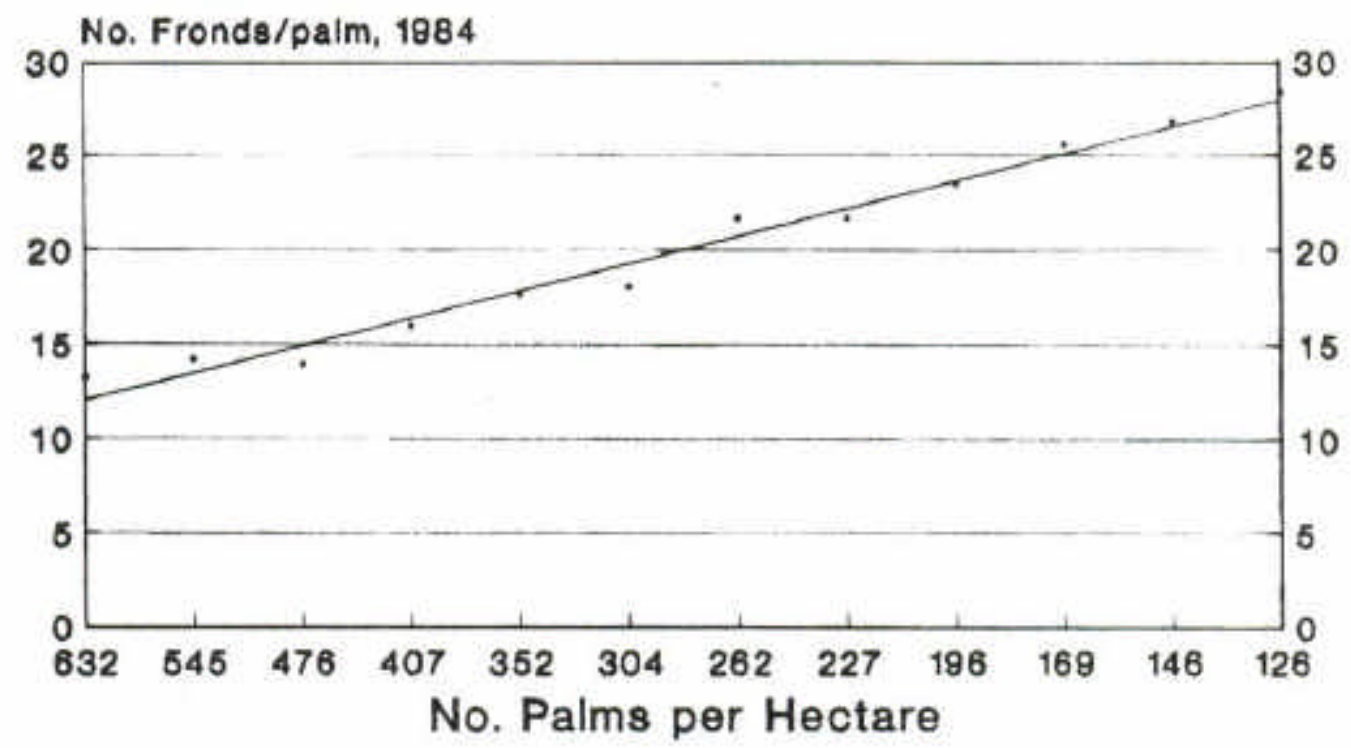

$\rightarrow$ No. Fronds/palm 1984

Fig 10. Spacing Trial ER 4, Kiritimati Trunk Height (m), 1984

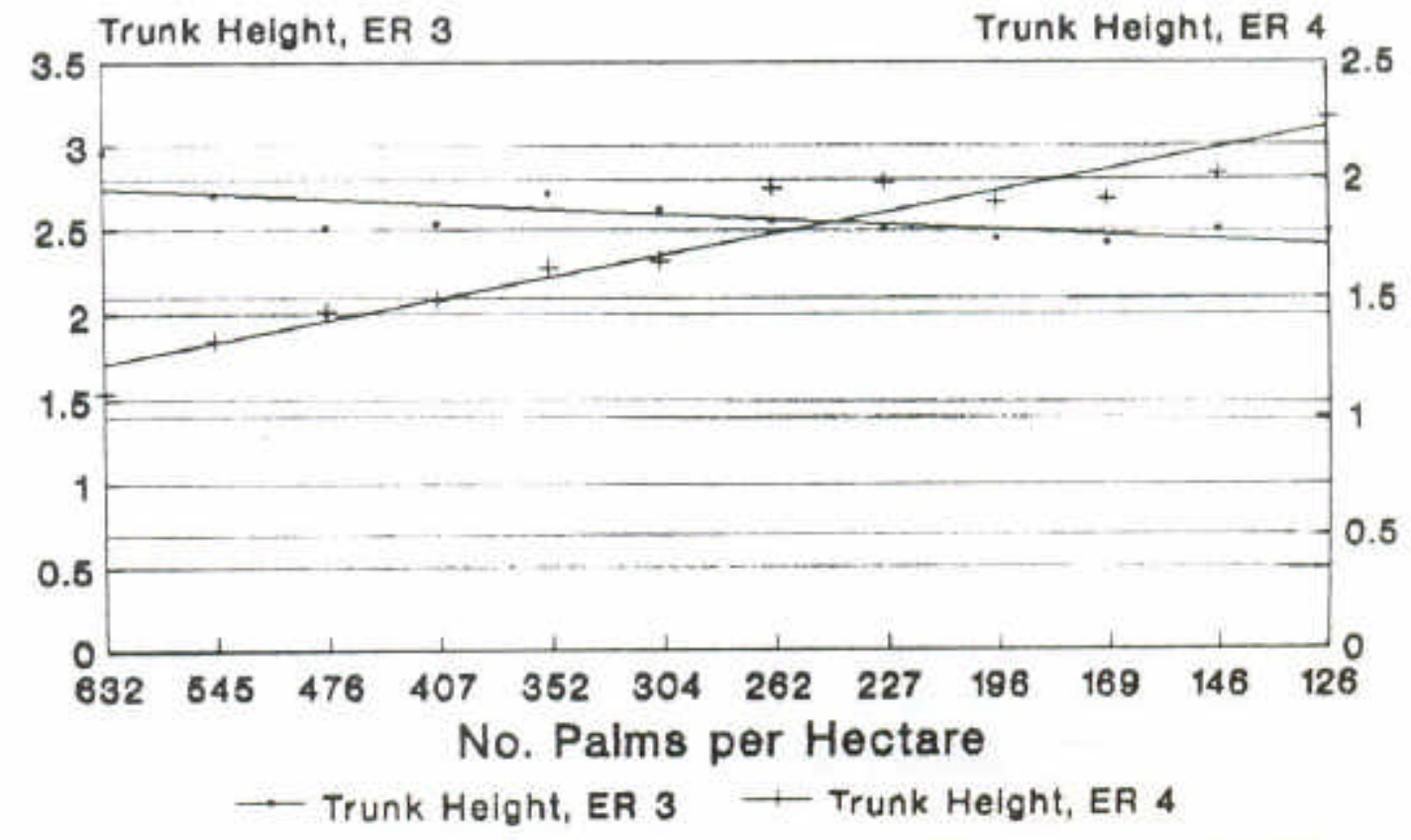




\section{b) Trial ER 1, Tarawa}

Trial ER 1 on Tarawa has been recorded for the nine years between 1984 and 1992. This period is representative of the behaviour of palms at different densities during the mature, closed canopy phase of their life. Results are discussed below and presented graphically in Figures 11 to 17. Although further recording at this stage is not necessary, it can be expected that once the palms are past the most productive phase and frond length starts to decrease with age (from about 30 years after planting), the optimum planting density in terms of maximum productivity per hectare will start to shift towards closer spacing. Further recording of the trial at that stage should prove to be illuminating.

\section{$\underline{\text { Yield/palm }}$}

Figures 11 a and 12a show the fitted curves for all years from 1984 to 1991 for nuts in bunches 5 to 8 and total nuts excluding bunches 1 to 4 respectively. Figures $11 \mathrm{~b}$ and $12 \mathrm{~b}$ show the fitted response curves for the long-term means for these parameters.

The analyses show that each year is best described by its own equation, but in every year except 1985 (which was very dry) the function is quadratic, with either palms/ha or depth to water table being significant as covariates in a number of years (indicated by an '*' in the legend on the graphs).

The mean fitted curves account for $30.4 \%$ and $10.4 \%$ of variance in nuts In bunches 5 to 8 and total nuts respectively. They show that the number of nuts/palm increases linearly with increased area/palm up, to about $169 \mathrm{palms} / \mathrm{ha}$. This equates to an area of $50.04 \mathrm{~m} / \mathrm{palm}$ or a palm spacing of $8.27 \mathrm{~m}$ triangular. At lower planting densities than this the palms do not appear to compete with each other, and thus the per palm yield flattens to a plateau of approximately equal yields at the lowest densities, ranging from 126 to 169 palms/ha.

There is a suggestion that at the lowest planting density, the yield per palm is lower than at the next lowest density, although this effect is not significant. This could be explained in terms of increased competition for nutrients between the coconuts and the ground cover. In this trial shrubs have been removed by hand but herbaceous plants, which consist mainly of the grass Lepunis repens, have been allowed to colonize the surface of the ground. At the closest spacing ground cover consists almost entirely of dead coconut fronds, and there is virtually no competition between the coconuts and any other species, but from planting densities of approximately $300 \mathrm{palms} / \mathrm{ha}$ or less the surface vegetation increases in inverse relationship to the planting density of coconuts, until at the lowest planting density the ground cover is complete and vigorous.

Yield/ha

The main objective of these trials is, of course, to identify the planting density which gives maximum productivity per unit area of land with the minimum of effort. The yield per hectare is therefore of greater interest than the yield per palm unless other considerations such as intercropping or the use of the trunks for timber are involved. 
Fig 11a. Spacing Trial ER 1, Tarawa

Number of Nuts in Bunches 5 to 8/Palm, All Years

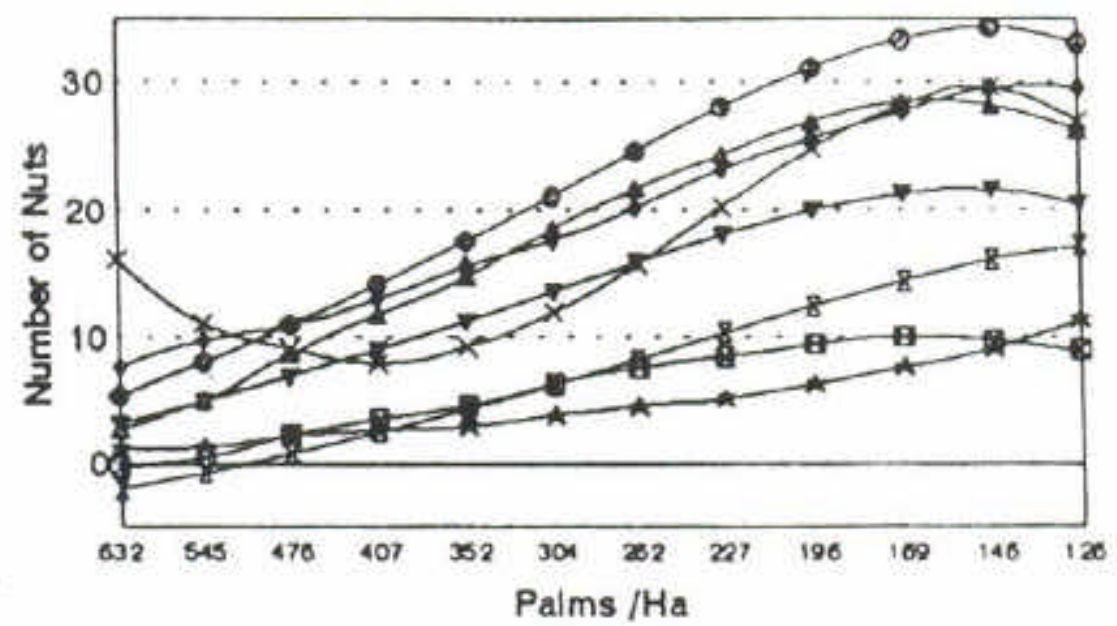

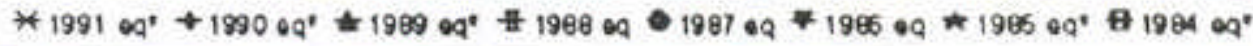

Fig 11b. Spacing Trial ER 1, Tarawa

Number of Nuts in Bunches 5 to 8/Palm, Mean, 1984-91

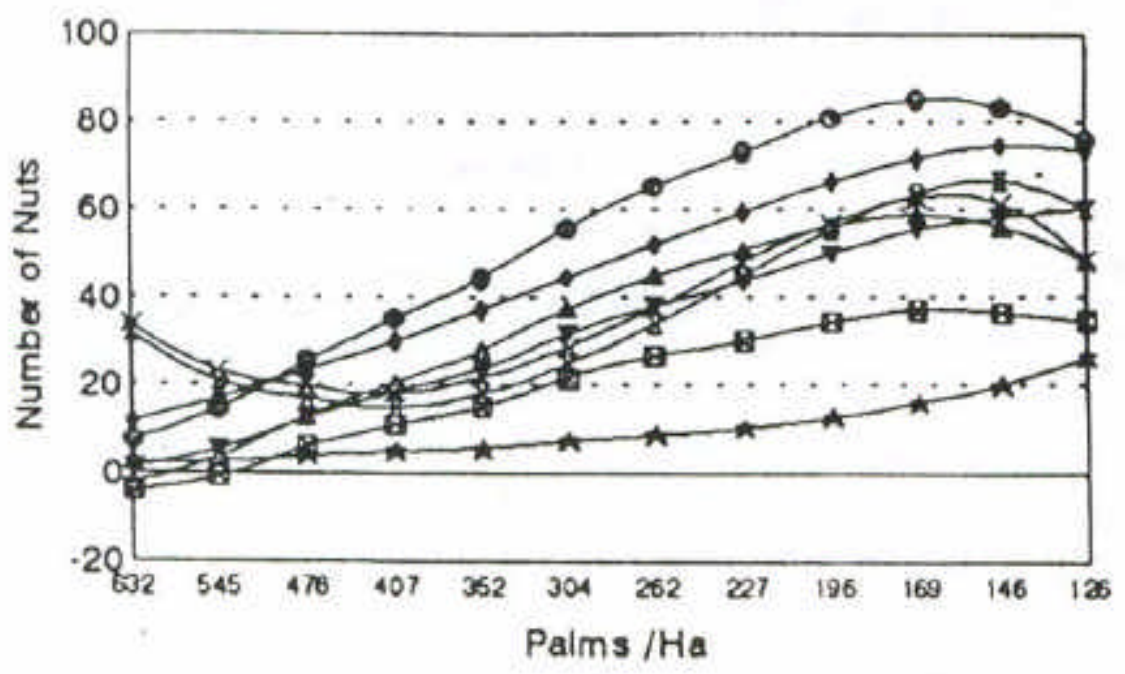

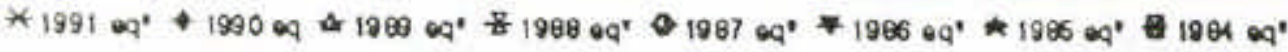


Fig 12b. Spacing Trial ER 1, Tarawa Total Nuts/Palm Excluding Bunches 1 to 4, Mean, 1984-91

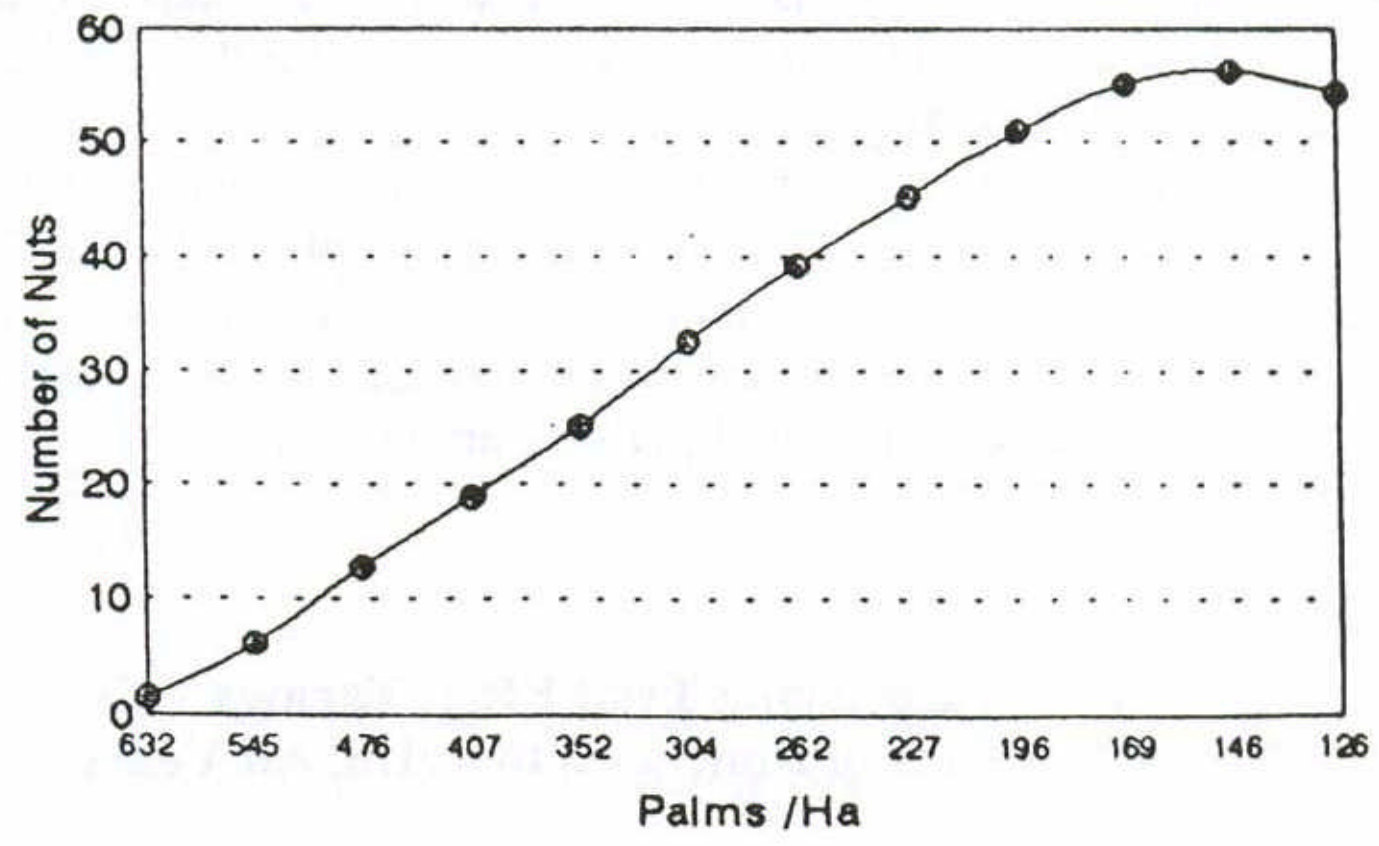

Figures 13a and 14a show the fitted curves for the individual years, and Figures $13 \mathrm{~b}$ and $14 \mathrm{~b}$ show die response curves for the long-term means for the two yield variates. The fitted curves for the individual years show a large range on the $\mathrm{Y}$ axis for nuts/ha. This is approximately related to rainfall (especially rainfall during the preceding year), with the dry years 1984, 1985 and 1988 giving the lowest yields. The form of the fitted curve is, apart from 1985 which is linear, quadratic with very weak or non-significant linear coefficients. This results in a hump- shaped curve. The apex of the hump is seen to shift between years, due presumably to such factors as current and previous nutritional status and moisture availability.

The curves for the mean data therefore have a similar hump shape, but with a relatively flat top, corresponding to approximately equal yield/ha for a wide range of palm densities. This range is from 169 to 304 palms/ ha for nuts in bunches 5 to 8 and between 196 and 304 palimba for total nuts. This equates to a range of planting distances of 6.16 to 8.27 meters triangular. It should be noted that this trial has been relatively well fertilized. Under these circumstances the optimum population density can be expected to be higher than un-fertilized palms, since the effect of fertilizers would be to reduce competition for nutrients at higher planting densities. Since the use of fertilizers by smallholders is uncommon, the recommended spacing for most smallholders should be towards the lower end of the range of population densities which give maximum yield per unit area of land.

$\underline{\text { Trunk height }}$

Absolute trunk- heights, and the annual increment in trunk height in relation to population density arc shown in Figures 15a and 15b. Results from individual years are not shown because it is, of course, the same trunks that arc being measured each year, so die pattern docs not change other than in terms of the annual increment 41 growth. The fitted curve is very significantly linear in form but with the quadratic and depth to water table coefficients also having some significance. It can be seen that the long-term trend is for more closely spaced palms to grow faster in response to competition for light. This is true across the entire range of densities tested here. 
Fig 13a. Spacing Trial ER 1, Tarawa

Number of Nuts in Bunches 5 to 8 /Ha, all years

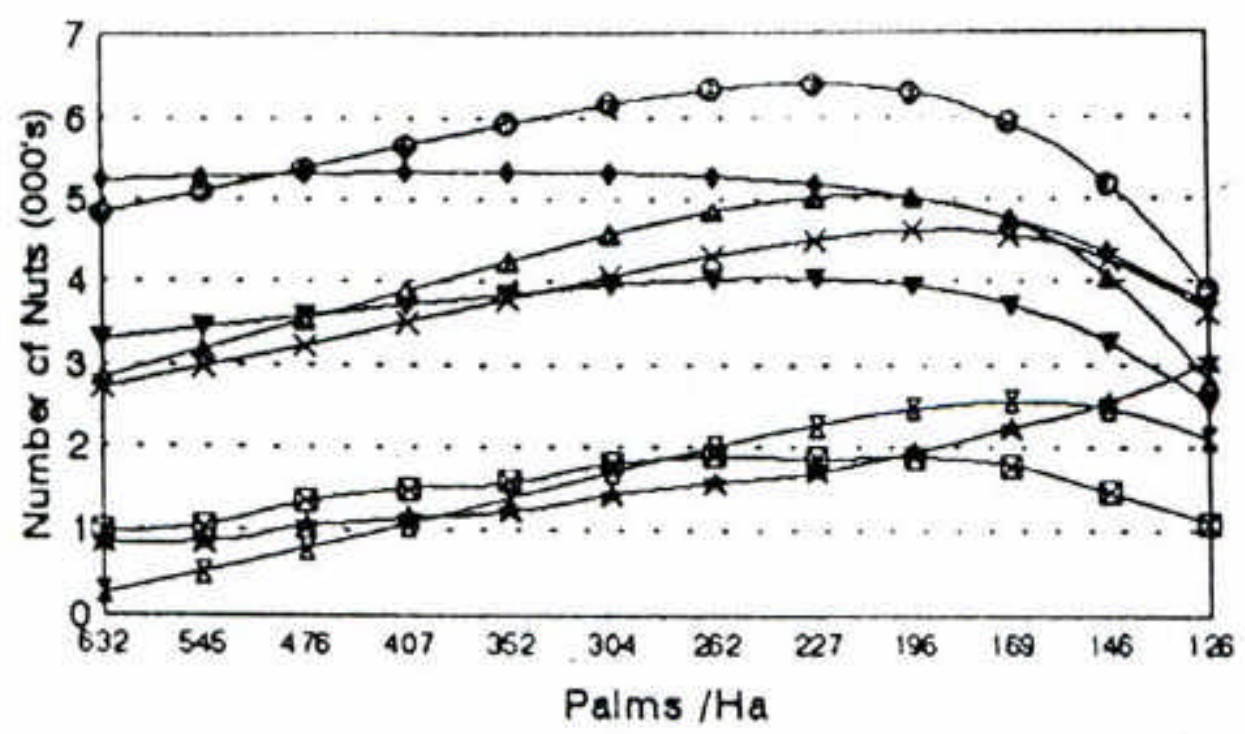

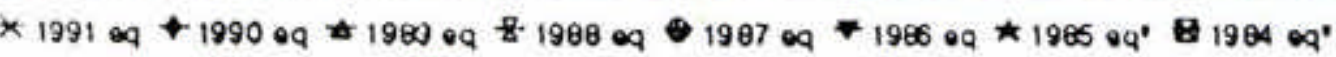

Fig 13b. Spacing Trial ER 1, Tarawa

Number of Nuts in Bunches 5 to 8 /Ha, Mean, 1984-91

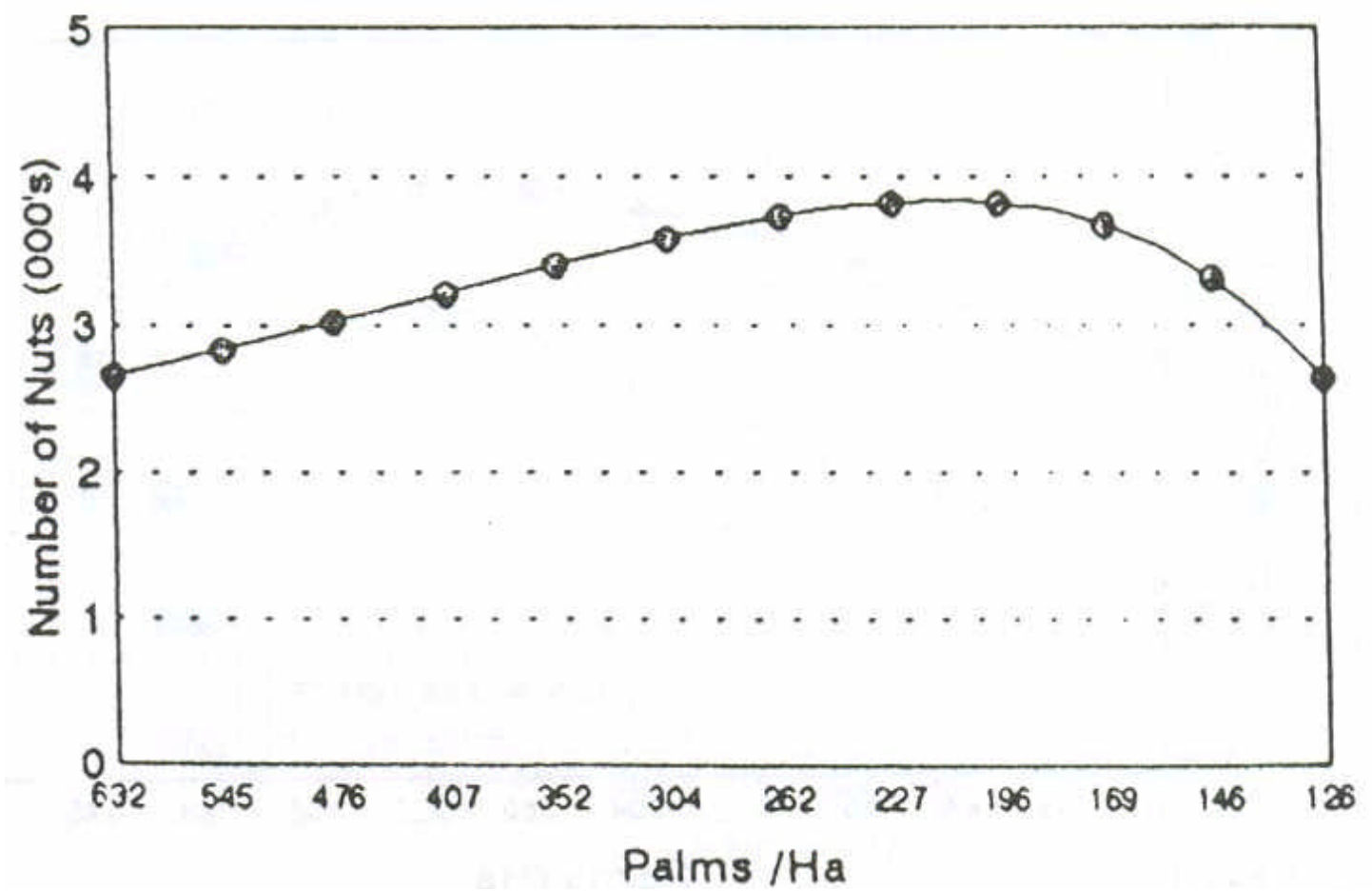


Fig 14a. Spacing Trial ER 1, Tarawa

Total Nuts/Ha Excluding Bunches 1 to 4, All Years

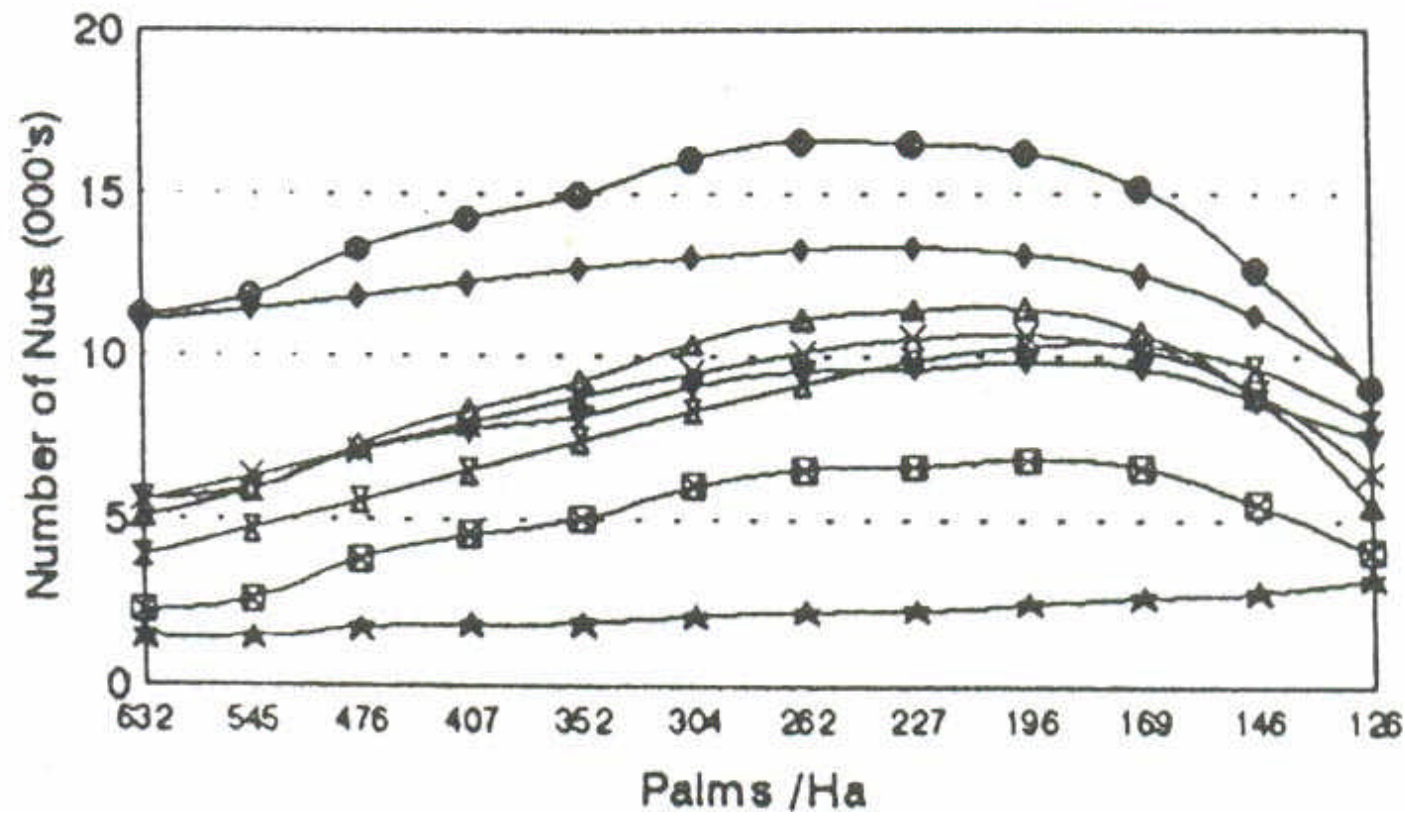

Fig 14b. Spacing Trial ER 1, Tarawa

Total Nuts/Ha Excluding Bunches 1 to 4, Mean, 1984-91

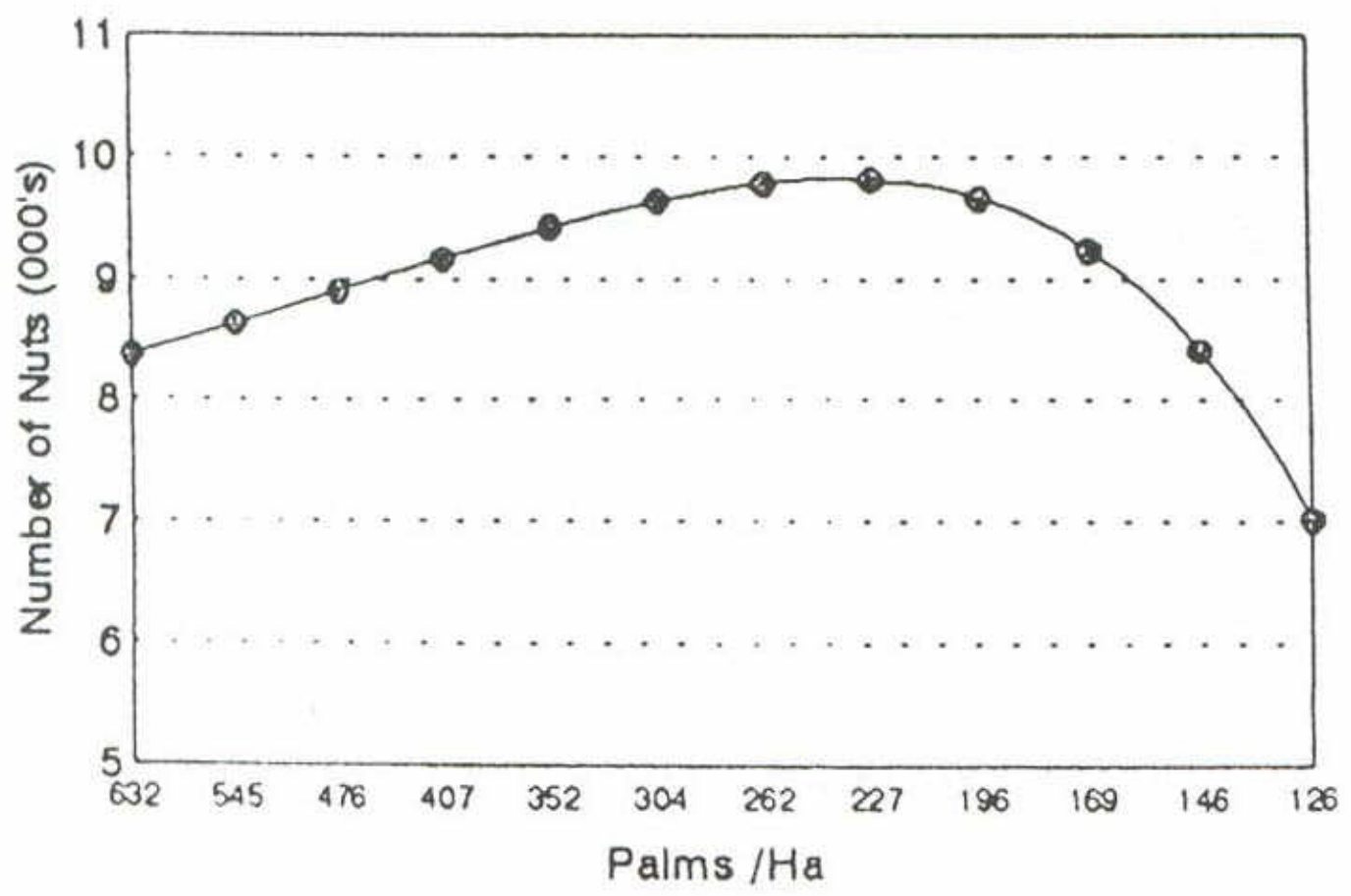


Fig 15a. Spacing Trial ER 1, Tarawa Trunk Height, 1991

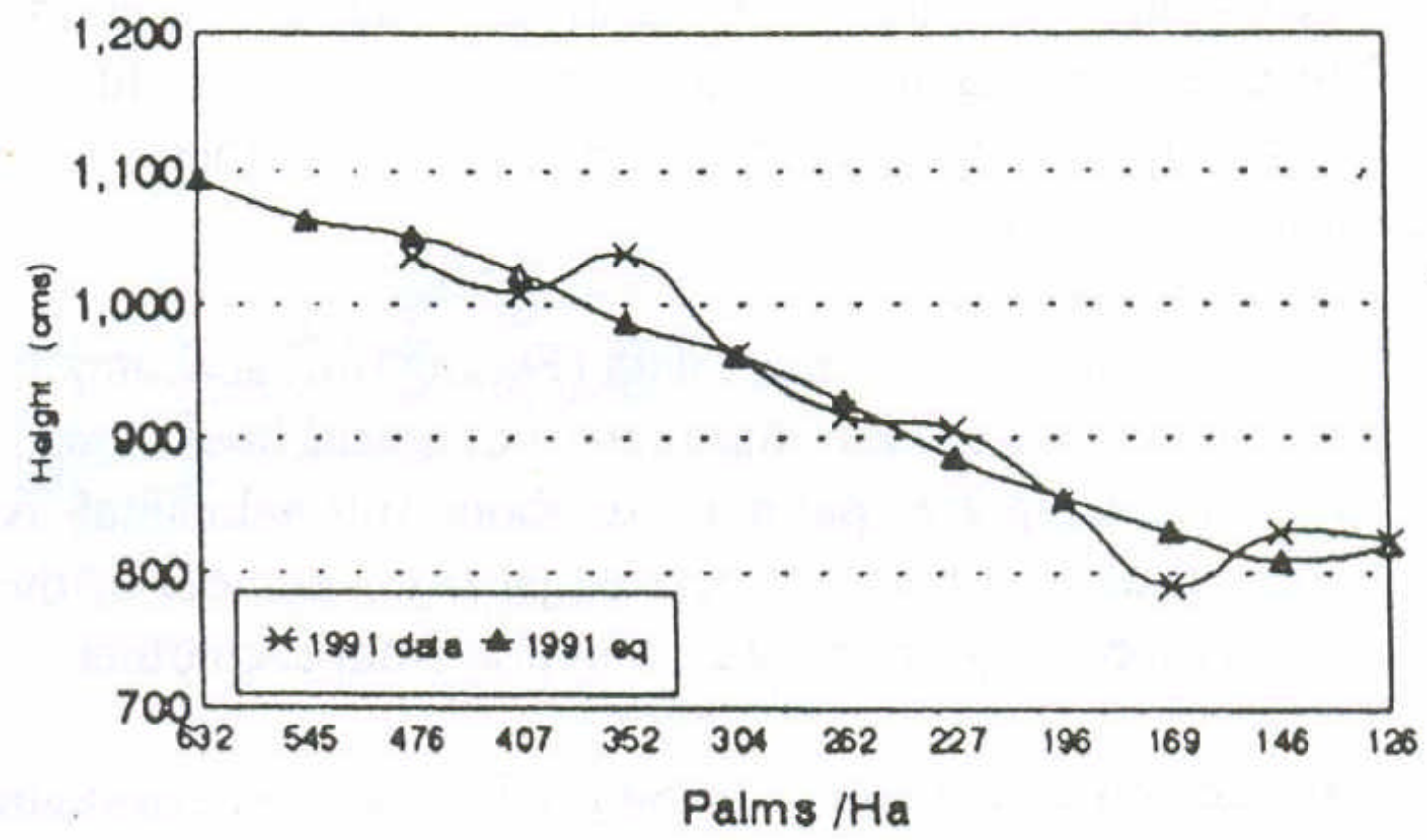

Fig 15b. Spacing Trial ER 1, Tarawa Trunk Height Increment, 1984-91

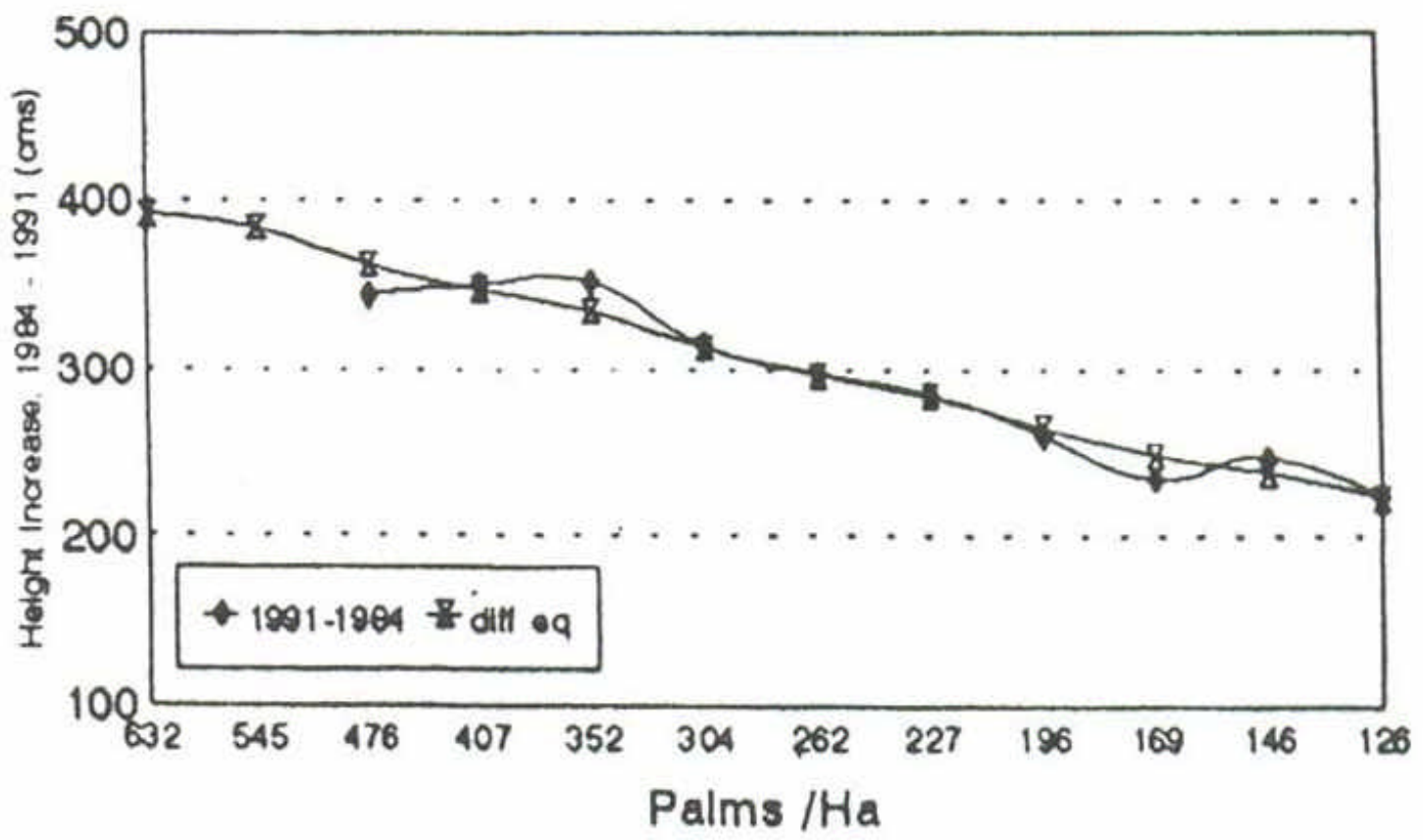


Fig 16a. Spacing Trial ER 1, Tarawa Number of Fronds/Palm, All Years

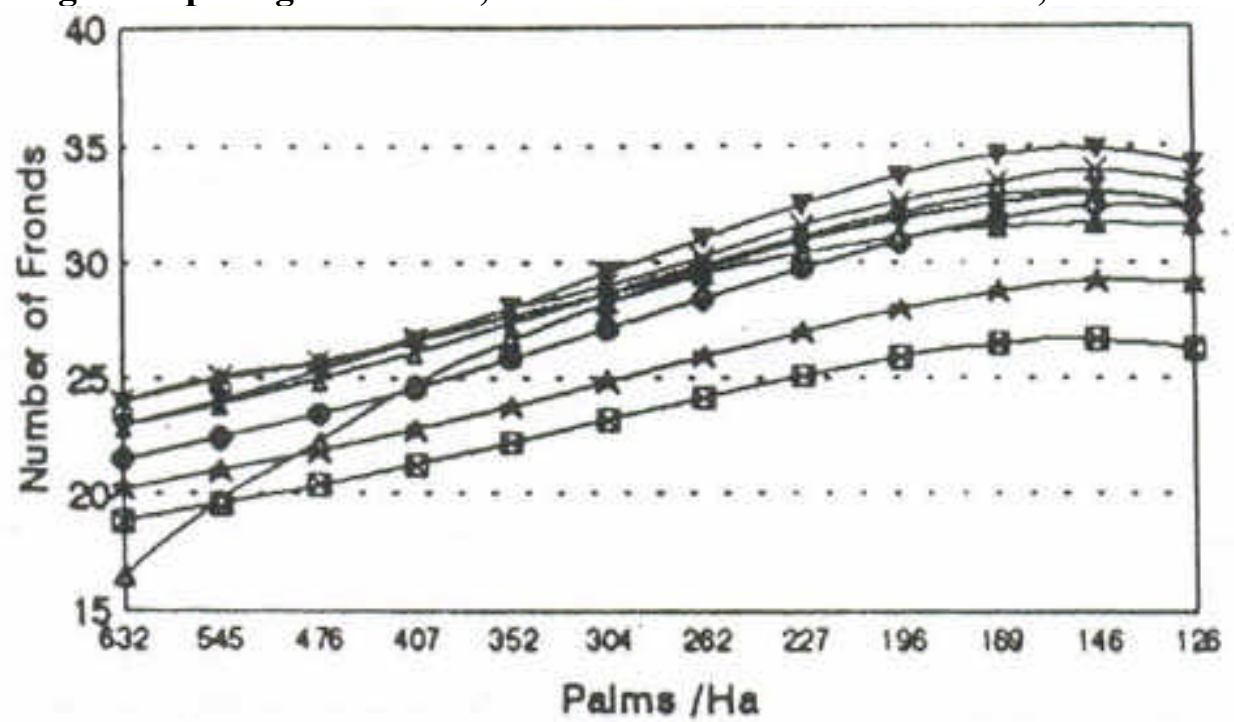

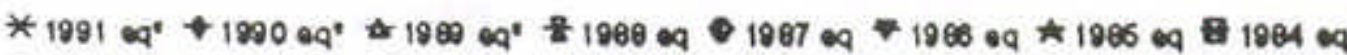

Fig 16b. Spacing Trial ER 1, Tarawa Number of Fronds/Palm, Mean, 1984-91

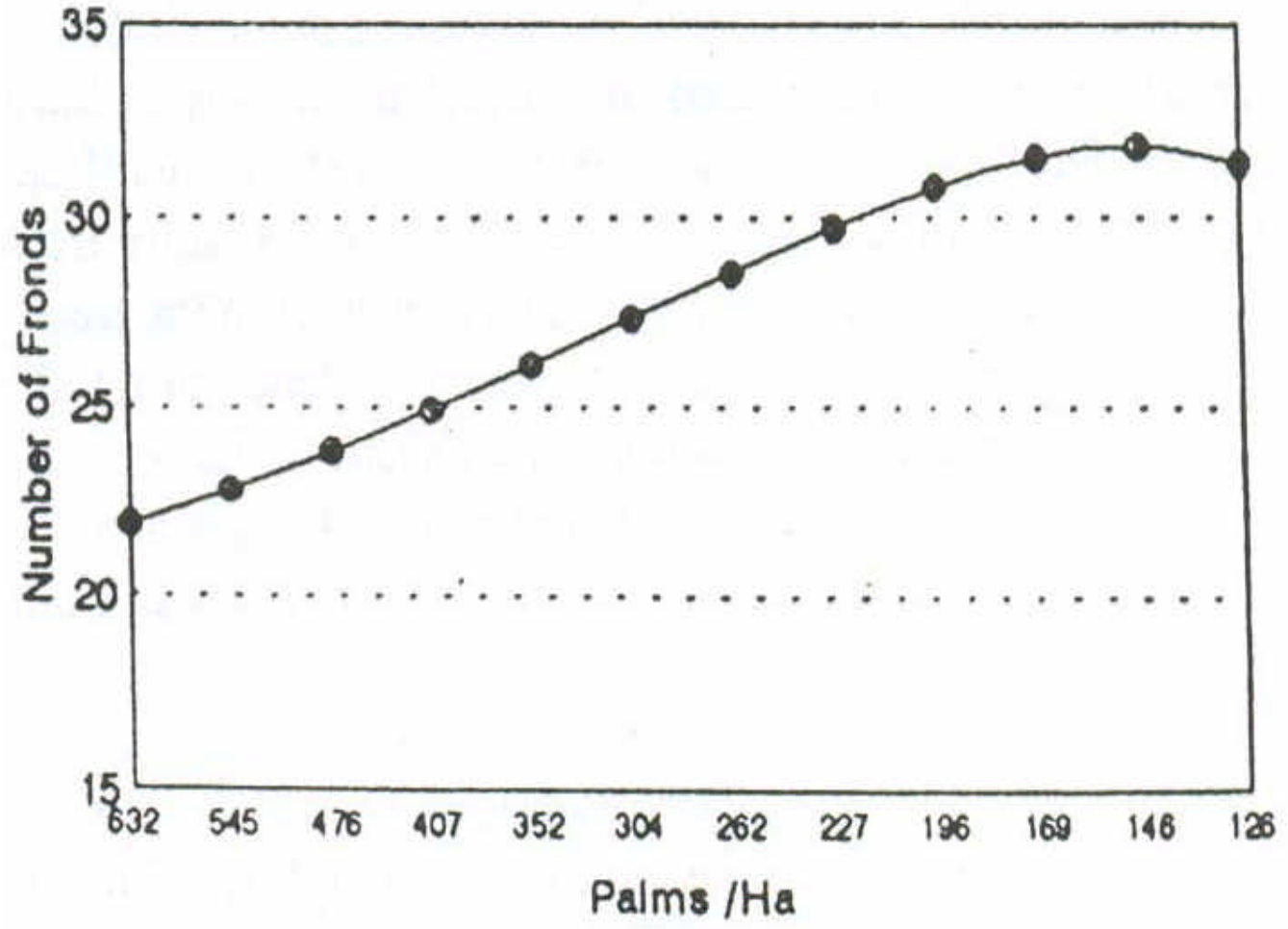


The practical implications of this arc dependent upon the uses to which the trees arc put. If harvesting of drinking nuts; or toddy is desirable, then excessively tall palms is an obvious disadvantage. If the trunks arc to be used for timber once the palms are over-aged, then die usefulness of the timber is an important consideration, because at the higher planting densities there arc fewer fronds per palm (see below), the rate of frond production is lower, leaf-scars on the trunks are further apart, and it can therefore be anticipated that the wood will contain fever vascular bundles, be less dense, and be of lower value for structural purposes.

Fronds/palm

As with the trials on Kiritimati, there is a very clear relationship between planting density, number of fronds per palm and the rate of frond (and therefore bunch) production (see Figures 16a and 16b). Each year is best fitted with its own equation, and the fit of equations to the data is good, accounting for $13.7 \%$ to $30.85 \%$ of the variance in the data. The functions are all quadratic, but in each year except 1984 and 1991 there are also highly significant linear coefficients.

The curve fitted to the mean data (Figure 16b) accounts for $34.3 \%$ of the variance and repeats the familiar pattern of a near linear increase in frond number with increasing area/palm, up to about 169 palms/ha. At the lower densities there is an asymptote of near equal frond number as the individual palms are then essentially growing in isolation from each other.

Information on the rate of frond production is not available for every year due to inconsistencies in the method of recording. The data for 1985-86 is presented in Figure 17 as an example. The response curve is quadratic, with a steep rise in the rate of frond production with decreasing planting densities down to 227 palms per hectare, and little or no difference between treatments at lower planting densities.

The rate of frond production (at around 15 per hectare), and number of fronds per palm at lower planting densities are relatively high in comparison with Local Tall coconuts in some other countries. In Solomon Islands, for instance, the rate of frond production is about 13 per annum, and the number of fronds per palm is usually within the range 18 to 24 . This may be a genetic characteristic of the Kiribati Tall Coconuts.

Since the fronds are the site of photosynthetic activity, and since the number of fronds per palm is correlated with the rate of frond (and therefore bunch) production, it is not surprising that there is a relationship between the number of fronds per palm and nut production. Apart from the obvious yield considerations, planting density has to be considered in terms of frond production if the fronds themselves are to be made use of. If the fronds are to be left to rot in situ, then there are advantages of planting at a high density, since the fallen fronds smother all surface vegetation and maintenance is reduced to a minimum.

\section{C) Trial ER 2, Butaritari}

Unfortunately only one year's yield results are available from this trial because the lease on the site expired, after which the nuts were harvested by the landowners. The information available is therefore insufficient to make recommendations with any degree of confidence. Results from 1984 were broadly similar to those from the trial on Tarawa, with the trend being linear over the higher planting densities with some evidence of a tailing off in the response curve at the wider spacing in ail yield variates. As an example, number of nuts per hectare excluding bunches 1 to 4 is given in Figure 18, and mean number of fronds per palm, 1984 to 1986, is given in Figure 19. 
Table 17. Spacing Trial ER 1, Tarawa Number of Fronds Produced, 1985-86

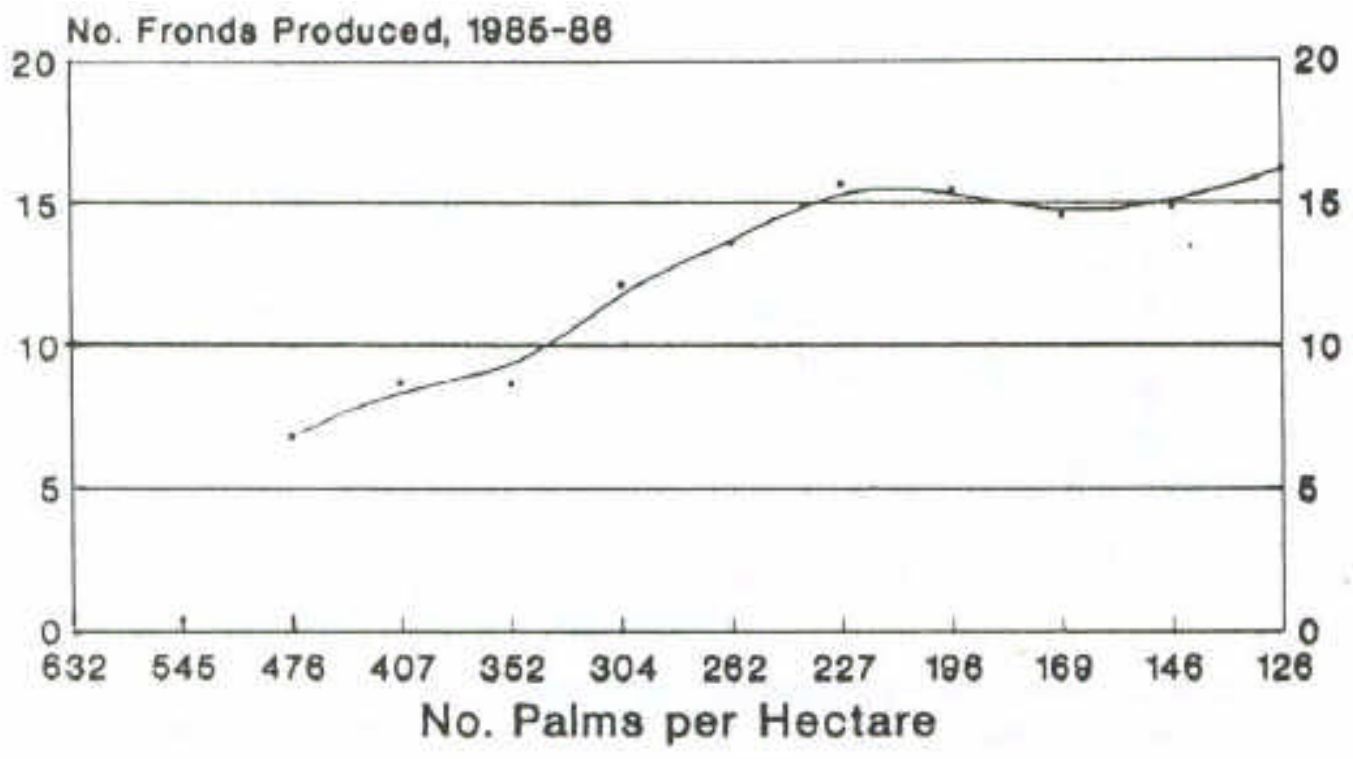

- No. Fronds Produced

Fig 18. Spacing Trial ER 2, Butaritari No. Nuts/ha, Excluding Bunches 1-4, 1984

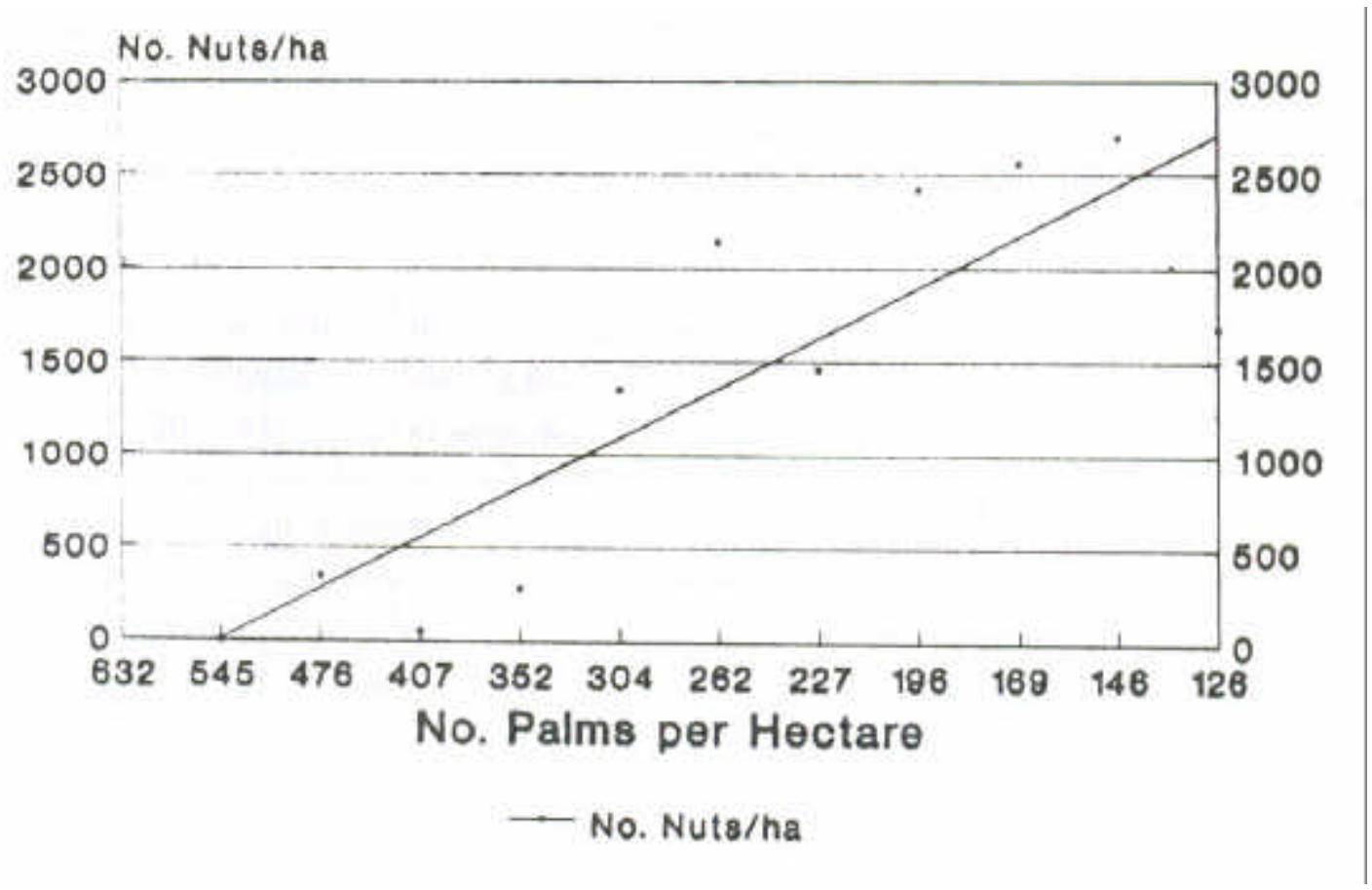


Fig 19. Spacing Trial ER 2, Butaritari Mean Number of Fronds per Palm 1984-1986

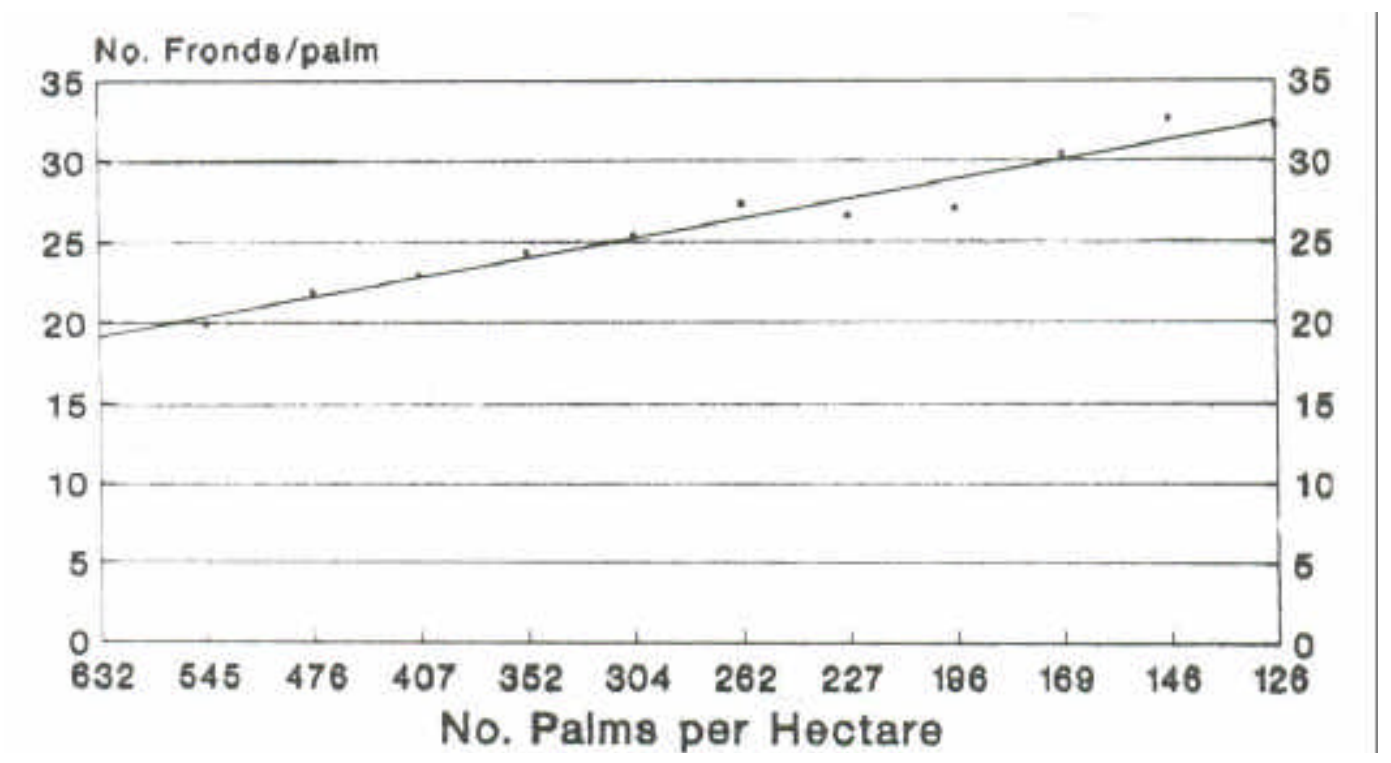

Apart from the paucity of information from this trial, the choice of site, being a disused air-strip, was unfortunate, and it is doubtful that the information would have, been relevant to normal high rainfall conditions even if further recording had been carried out.

\section{CONCLUSIONS}

It is clear from the results of the trials on Kiritimati that in conditions of very low rainfall ( $870 \mathrm{~min} /$ annum) the optimum planting density is outside of the range covered by these trials, i.e. is something less than 126 palms per hectare, which corresponds to a spacing of $8.9 \mathrm{~m}$ square or $9.6 \mathrm{~m}$ on the triangle.

On islands which receive around 2,000 nun rainfall per annum, and the coconuts are adequately fertilized, the optimum population density in terms of maximum productivity of nuts per unit area of land is within the range 169 to 304 palms per hectare, during the first 22 years of the life of the palms. Within this range of planting densities there is little difference in yield because productivity per palm is inversely related to number of palms per hectare. The choice of spacing is therefore dependent upon other factors, such as the labour involved in the digging of planting holes, the uses to which the palms are to be put, whether intercropping is to be practised, and the availability of labour for subsequent maintenance,

Until recently it has been the recommended practice to dig planting holes of at least one meter cube in Kiribati, and on the islands which receive less than 1500 nun rainfall per annum, holes as much as four meters deep have sometimes been dug to enable the roots of the seedlings to tap the water lens as soon as possible. Under these circumstances the widest spacing which still gives optimum yield per hectare is desirable. The widest spacing is also desirable if the palms are to be tapped for toddy, climbed for drinking nuts, used for high quality timber, or if die fronds are an important resource because trunk height and frond production are inversely related to population density, and it is thought that the wood of the palms at the wider spacing will be of higher density than that at the close spacing. If intercropping is to be practiced it is likely that the optimum spacing of the coconuts could be somewhat wider than that which gives maximum return per unit area of the coconuts, depending upon the relative value of the two crops, and whether intercropping is to be 
permanent or short-term. If labour for maintenance is in short supply, a relatively close spacing might be desirable, since the coconuts will compete more effectively with surface vegetation. It must be recognized, however, that at the closer spacing the palms will take longer to come into production and achieve maximum productivity.

Although information from the trial on Butaritari is inconclusive, it has been observed in the trial on Tarawa that the optimum spacing shifts from year to year in response to the rainfall during the previous season. It can therefore be inferred that the recommended planting density should be varied from island to island according to the average annual rainfall.

\section{RECOMMENDATIONS}

On islands which receive less than 1,000 nun rainfall per annum the planting density should be less than 126 palms per hectare. A spacing of 10 meters square (100 palms per hectare) is tentatively recommended.

On islands on which the average annual rainfall is $2,000 \mathrm{~mm}$ or more, and the palms are to be fertilized, the planting density can be anything between 170 to 300 palms per hectare, yields being nearly the same within this range. In general, planting at the lower end of the population density has advantages in terms of precocity, the effort involved in establishment, and reduced expenditure on inputs, especially fertilizer. However on islands of higher rainfall a closer spacing is likely to give higher productivity. If fertilizers are not to be used, and especially on islands which receive significantly less than 2,000 nut rainfall per annum, the optimum planting density is probably in the region of 150 palms per hectare. A convenient round figure is a spacing of $9 \mathrm{~m}$ triangular, which gives a population density of 143 palms per hectare.

A significant exception to these recommendations would be if long-term intercropping is to be practiced, when a much wider spacing might be chosen to accommodate the requirements of the other crop. This would be dependent to a large extent upon the relative value of the two crops.

\section{ACKNOWLEDGEMENTS}

The authors are deeply indebted to Mr. K Martin, formerly Biometrician at East Malling Research Station, UK, who designed the trials, analyzed the results from 1969 until 1984, and provided biometrical advice during that period, and equally to Mr. K Ryder of Rothamsted Experimental Station, LJK, who continued to provide biometrical assistance from 1985 until 1992. 


\section{REFERENCES}

CATALA, R L A (1957). Report on Gilbert Islands: Some Aspects of Human Ecology. Atoll Res. Bull. 59.

NELDER, J A (1962). New Kinds of Systematic Designs for Spacing Experiments. Biometrics; 19, 283.

The information presented in this paper has been drawn from the following reports by the authors.

BARR, J J F (1992). Technical Report on Coconut Research in Kiribati, 1990-1992. Ministry of the Environment and Natural Resources Development, Division of Agriculture, Kiribati.

TREWREN, K (1985). Crop Research in Kiribati, 1982-1984. Ministry of Natural Resources Development, Division of Agriculture, Kiribati.

TREWREN, K (1986). Annual Technical Report on Crop Research in Kiribati, 1985. Ministry of Natural Resources Development, Division of Agriculture, Kiribati.

TREWREN, K (1987). Annual Technical Report on Crop Research in Kiribati, 1986. Ministry of Natural Resources Development, Division of Agriculture, Kiribati. 